\title{
Communication Behavior Changes Between Patients With Diabetes and Healthcare Providers Over 9 Years: Retrospective Cohort Study
}

Arriel Benis ${ }^{1,2}$, PhD; Refael Barak Barkan ${ }^{3}, \mathrm{MD}, \mathrm{PhD}$; Tomer Sela ${ }^{4}, \mathrm{BA}, \mathrm{MBA}$; Nissim Harel ${ }^{3}$, PhD

\footnotetext{
${ }^{1}$ Faculty of Technology Management, Holon Institute of Technology, Holon, Israel

${ }^{2}$ Clalit Research Institute, Clalit Health Services, Tel-Aviv, Israel

${ }^{3}$ Faculty of Sciences, Holon Institute of Technology, Holon, Israel

${ }^{4}$ Online Division, Clalit Health Services, Tel-Aviv, Israel
}

Corresponding Author:

Arriel Benis, PhD

Faculty of Technology Management

Holon Institute of Technology

Golomb St 52

POB 305

Holon

Israel

Phone: 97235026892

Email: $\underline{\text { arrielb@hit.ac.il }}$

\section{Abstract}

Background: Health organizations and patients interact over different communication channels and are harnessing digital communications for this purpose. Assisting health organizations to improve, adapt, and introduce new patient-health care practitioner communication channels (such as patient portals, mobile apps, and text messaging) enhances health care services access.

Objective: This retrospective data study aims to assist health care administrators and policy makers to improve and personalize communication between patients and health care professionals by expanding the capabilities of current communication channels and introducing new ones. Our main hypothesis is that patient follow-up and clinical outcomes are influenced by their preferred communication channels with the health care organization.

Methods: This study analyzes data stored in electronic medical records and logs documenting access to various communication channels between patients and a health organization (Clalit Health Services, Israel). Data were collected between 2008 and 2016 from records of 311,168 patients diagnosed with diabetes, aged 21 years and over, members of Clalit at least since 2007, and still alive in 2016. The analysis consisted of characterizing the use profiles of communication channels over time and used clustering for discretization purposes and patient profile building and then a hierarchical clustering and heatmaps to visualize the different communication profiles.

Results: A total of 13 profiles of patients were identified and characterized. We have shown how the communication channels provided by the health organization influence the communication behavior of patients. We observed how different patients respond differently to technological means of communication and change or don't change their communication patterns with the health care organization based on the communication channels available to them.

Conclusions: Identifying the channels of communication within the health organization and which are preferred by each patient creates an opportunity to convey messages adapted to the patient in the most appropriate way. The greater the likelihood that the therapeutic message is received by the patient, the greater the patient's response and proactiveness to the treatment will be.

International Registered Report Identifier (IRRID): RR2-10.2196/10734

(J Med Internet Res 2020;22(8):e17186) doi: $\underline{10.2196 / 17186}$ 


\section{KEYWORDS}

population characteristics; eHealth; mHealth; consumer health informatics; delivery of health care; machine learning; clustering; quality of health care; point-of-care systems; physician-patient relations

\section{Introduction}

\section{Background}

Communications between patients and health care professionals are based on a range of communication channels [1-10] and influenced by cultural factors [11-13]. Traditional channels supporting these interactions are face-to-face visits and phone calls. Health management organizations (HMOs) are capitalizing on the digital revolution $[8,14]$ and innovating and providing patients with new digital tools [15]. Their goal is to provide patients with alternative ways for asking, getting, and sharing health-related information and knowledge [2-6,9,10,16].

Interactions between patients and health care professionals in an HMO must be analyzed over time to better understand the potential impacts of technological changes. Data mining and machine learning methodologies are used in the analysis of a large amount of data. Several techniques can be used to define or redefine clusters of patients based on sociodemographics and biological and clinical data $[17,18]$. We are not aware of an attempt to cluster patients based on communication, sociodemographic, and bioclinical characteristics, let alone at a large scale involving data from hundreds of thousands of patients collected for almost a decade. In this paper, we are disclosing the results of this kind of approach [19].

\section{Aims and Objectives}

This retrospective data study aims at assisting health care administrators in defining and developing new communication channels and policy makers in improving and personalizing communication between patients and health care professionals (eg, physicians and nurses). By expanding the capabilities of currently available communication channels and introducing new channels, we hope to help policy makers enhance the accessibility of health care professionals and organizations and improve the quality of patient follow-up and treatment adherence and the overall patient experience with HMO services [13,19-22].

This work characterizes the use profiles of chronic patients with the communication channels available at Clalit Health Services, a large HMO in Israel, between 2008 and 2016. The use profiles are then associated with sociodemographic and medical patient profiles.
The leading objective of this analysis is to propose new ways to promote the use of the most appropriate communication channels based on the patient profile. An additional objective is to recommend sociological and technological ways that should be developed for increasing the quality and effectiveness of the patient-health care professional communication and interaction.

\section{Hypotheses}

This retrospective research is led by 3 hypotheses:

- Preferred communication channels of a patient with the health care professional in an HMO influence follow-up and clinical outcomes.

- Adoption of a new communication channel by a patient is affected by their sociodemographic and clinical profile.

- Introducing a new communication channel impacts the use of existing communication channels.

This research focuses on quantifying these behaviors. The goal is to identify sociodemographic and bioclinical attributes affecting engagement with newly launched communication channels. This research characterizes changes in the use of existing communication channels once a new communication channel is introduced.

\section{Methods}

The study design including details about material and methods has been described and published elsewhere [19]. Ethical approval for the study was granted by the Clalit ethical committee.

\section{Material}

Data were extracted from Clalit electronic medical records (EMRs), which include documented access to various communication channels between patients and Clalit. Clalit is the largest Israeli HMO, with 4.53 million insured members (53\% of the Israeli population) in 2016. Since 1998, Clalit's EMRs have been stored in a data warehouse $[19,23,24]$.

The period of time investigated in this research allowed us to analyze the launch of new communication channels such as a website, mobile apps, and text messaging (short message service [SMS]) system (Figure 1) and identify communication behavior changes as functions of time and the introduction of new communication channels. 
Figure 1. Communication channel introduction over time.

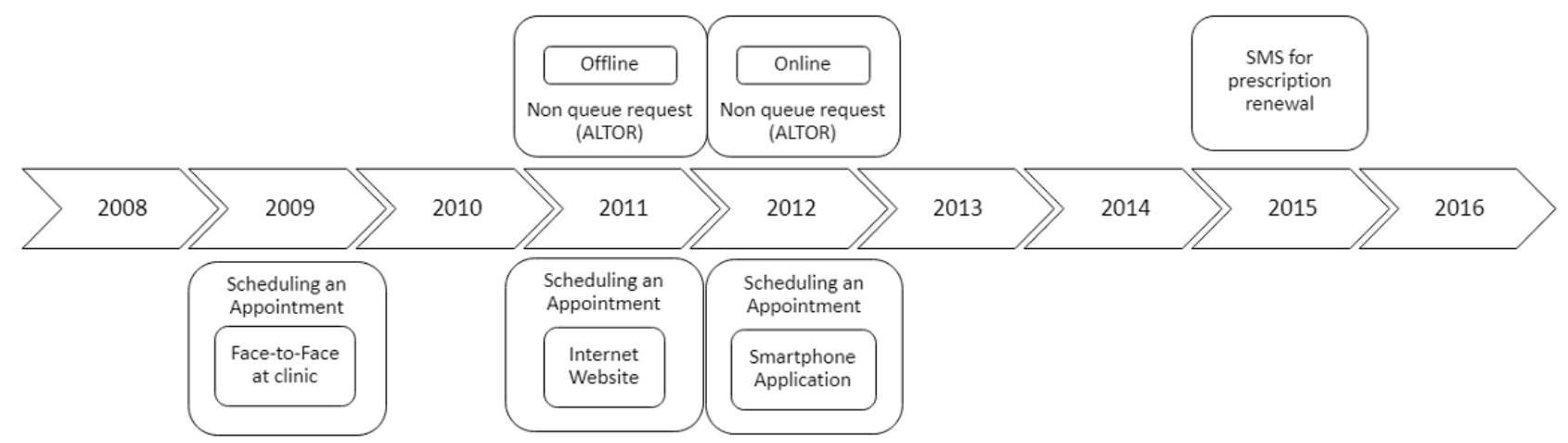

The cohort consisted of patients aged 21 years and older, diagnosed with diabetes, members of Clalit for at least 1 year before 2008, and still alive in 2016 [25-27].

\section{Analysis Process}

\section{Overview}

This research used the knowledge discovery in databases (KDD) framework [28-30]. Our study analyzes communication channel use over a 9-year period wherein Clalit introduced and changed the methods of interactions between patients, health care professionals, and administrative staff. We identified the sociodemographic and bioclinical characteristics for each communication profile and qualitatively evaluated the influence of the profile on patient engagement and follow-up quality.

We ran 1-dimensional and multidimensional statistical tools and different data mining algorithms, which were used during the data cleansing step [31,32]. The data extraction, preprocessing, data mining, and information visualization are briefly described below. Details have been published elsewhere [19].

\section{Data Extraction}

Data extracted from the Clalit data warehouse for each patient included sociodemographic [19] and bioclinical [25,26,33-37] data and contacts with the HMO using communication channels.

\section{Data Preprocessing}

Cleansing of extracted data reduced noise by detecting and removing or correcting outliers [38,39]. An outlier is a data measurement that is inconsistent with other historical measurement data of the same individual. For some measurements (eg, BMI), specific algorithms have been developed in-house by Clalit. In the absence of these algorithms, statistical approaches and machine learning algorithms were used [40-44].

Several machine learning algorithms require data reformulation to support data categorization or grouping numerical, categorical, or textual data [41,45-48]. For some attributes that don't have predefined scales, we used the k-means clustering algorithm to discretize the data into 6 groups: very small, small, small-to-moderate, moderate, moderate-to-large, and large. The cluster bounds were validated by a domain expert (Table 1). 
Table 1. Gradient reformulation and ranges of values related to each resource consumption level.

\begin{tabular}{|c|c|c|c|c|c|c|c|}
\hline \multirow[t]{2}{*}{ Characteristic } & \multicolumn{7}{|c|}{ Gradient reformulation } \\
\hline & $\mathrm{N} / \mathrm{A}^{\mathrm{a}}$ & $\begin{array}{l}\text { No (very } \\
\text { small) }\end{array}$ & Small & $\begin{array}{l}\text { Small to } \\
\text { moderate }\end{array}$ & Moderate & $\begin{array}{l}\text { Moderate to } \\
\text { large }\end{array}$ & Large \\
\hline \multicolumn{8}{|l|}{ Contact with health care provider } \\
\hline Physician consultation & N/A & 0 & $1-7$ & $8-19$ & $20-28$ & $29-51$ & $52+$ \\
\hline Nurse consultation & N/A & 0 & $1-3$ & $4-5$ & $6-8$ & $9-14$ & $15+$ \\
\hline Hospitalization & N/A & 0 & 1 & 2 & 3 & $4-5$ & $6+$ \\
\hline $\mathrm{ED}^{\mathrm{b}}$ visit & N/A & 0 & 1 & 2 & 3 & 4 & $5+$ \\
\hline \multicolumn{8}{|l|}{ Scheduling an appointment } \\
\hline Face-to-face at clinic & N/A & 0 & 1 & 2 & $3-4$ & $5-8$ & $9+$ \\
\hline Call to clinic or call center & N/A & 0 & $1-2$ & $3-5$ & $6-9$ & $10-15$ & $16+$ \\
\hline Smartphone app & N/A & 0 & 1 & 2 & $3-4$ & $5-8$ & $9+$ \\
\hline Internet website & N/A & 0 & 1 & $2-3$ & $4-6$ & $7-10$ & $11+$ \\
\hline \multicolumn{8}{|l|}{ Nonqueue request } \\
\hline Online & N/A & 0 & $1-3$ & $4-12$ & $13-24$ & $25-45$ & $46+$ \\
\hline Offline that must be done online & N/A & 0 & $1-17$ & $18-44$ & $45-74$ & $75-113$ & $114+$ \\
\hline Offline & N/A & 0 & $1-17$ & $18-44$ & $45-74$ & $75-113$ & $114+$ \\
\hline \multicolumn{8}{|l|}{ Pharmacy } \\
\hline Overall recorded visits & N/A & 0 & $1-4$ & $5-12$ & $13-26$ & $27-42$ & $43+$ \\
\hline \multicolumn{8}{|l|}{ SMS $^{\mathbf{c}}$ for prescription renewal } \\
\hline Proposition sent by $\mathrm{HMO}^{\mathrm{d}}$ to patient & N/A & 0 & 1 & 2 & 3 & 4 & $5+$ \\
\hline Approval sent by patient to HMO & N/A & 0 & 1 & 2 & 3 & 4 & $5+$ \\
\hline
\end{tabular}

${ }^{\mathrm{a}} \mathrm{N} / \mathrm{A}$ : not applicable.

${ }^{\mathrm{b}} \mathrm{ED}$ : emergency department.

${ }^{\mathrm{c}}$ SMS: short message service.

${ }^{\mathrm{d}} \mathrm{HMO}$ : health management organization.

\section{Data Mining and Information Visualization}

As we don't have prior knowledge on communication channel use, we used unsupervised learning algorithms, mainly k-means and hierarchical clustering [47-56] combined with the Ray-Turi criterion [49].

To investigate communication patterns over time, we built heatmaps for each year between 2008 and 2016 based on the previously generated hierarchical clustering of 2016 data. Furthermore, we concatenated the communication profile of each discovered patients' clusters over the years [56]. This visualization helps identify changes in communication profiles for each cluster.

All computations described above were performed using R 3.3.1 (R Foundation for Statistical Computing) with the following packages: data.table [57] (computing efficiency given the large data size), cluster [58] (k-means and hierarchical clustering), and gplots [59] (drawing heatmaps and hierarchical clustering dendrograms).

\section{Results}

\section{Overview}

A total of 311,168 individuals were included in the study cohort. As means of communication with health care professionals have changed throughout the research period, we chose 2016 as the base year to which communication behavior is compared because during this year, health care customers were offered the most diverse communication channels. Applying the methodology described above to the 2016 data revealed 13 communication profiles. The resulting heatmap is presented in Figure 2. Two main types of communication behaviors are evident from the figure. The first main cluster consists of 6 communication profiles describing low-to-moderate health care services consumption. The second one consists of 7 communication profiles describing moderate-to-high health care services consumption.

All differences between the sociodemographic, biological, clinical (Tables 2 and 3), and communication characteristics between the overall population and each one of the clusters were statistically significant $(P<.001)$. 
Figure 2. Communication patterns in 2016 of 311,168 patients with diabetes (members of the Clalit Health Services). HMO: health management organization.

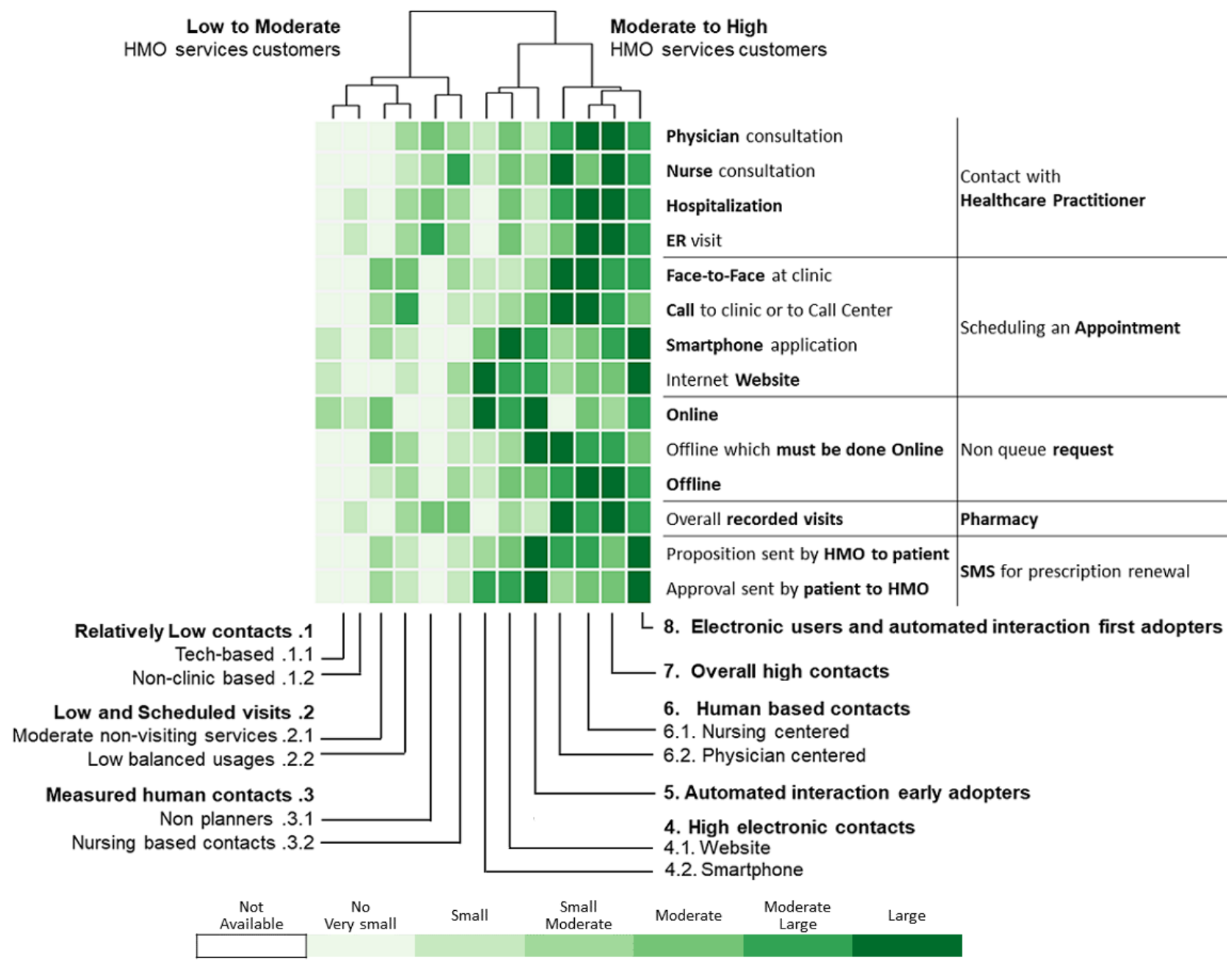


Table 2. Sociodemographic, clinical, and biological measurements data summary for patients with diabetes, in 2016, having a low-to-moderate health care services consumption.

\begin{tabular}{|c|c|c|c|c|c|c|c|}
\hline \multirow[t]{2}{*}{ Characteristic } & \multirow{2}{*}{$\begin{array}{l}\text { Overall } \\
(\mathrm{n}=311,168)\end{array}$} & \multicolumn{2}{|c|}{ Relatively low contacts } & \multicolumn{2}{|c|}{ Low and scheduled visits } & \multicolumn{2}{|c|}{ Measured human contacts } \\
\hline & & $\begin{array}{l}\text { Tech-based } \\
(\mathrm{n}=35,719)\end{array}$ & $\begin{array}{l}\text { Non-clinic- } \\
\text { based } \\
(\mathrm{n}=34,060)\end{array}$ & $\begin{array}{l}\text { Moderate nonvis- } \\
\text { iting services } \\
(\mathrm{n}=49,540)\end{array}$ & $\begin{array}{l}\text { Low balance } \\
\text { use }(n=41,735)\end{array}$ & $\begin{array}{l}\text { Nonplanners } \\
(\mathrm{n}=22,275)\end{array}$ & $\begin{array}{l}\text { Nursing-based } \\
\text { contacts } \\
(n=29,197)\end{array}$ \\
\hline \multicolumn{8}{|l|}{ Gender, n (\%) } \\
\hline Female & $156,269(50.2)$ & $15,669(43.9)$ & $17,173(50.4)$ & $24,609(49.7)$ & $22,525(54.0)$ & $11,264(50.6)$ & $15,463(53.0)$ \\
\hline Male & $154,899(49.8)$ & $20,050(56.1)$ & $16,887(49.6)$ & $24,931(50.3)$ & $19,210(46.0)$ & $11,011(49.4)$ & $13,734(47.0)$ \\
\hline $\begin{array}{l}\text { Age in years, median } \\
\left(\mathrm{IQR}^{\mathrm{a}}\right)\end{array}$ & $68(60-77)$ & $60(51-68)$ & $69(61-79)$ & $67(60-76)$ & $70(62-78)$ & $68(60-76)$ & $70(62-79)$ \\
\hline \multicolumn{8}{|l|}{ Immigrant, n (\%) } \\
\hline No & $152,533(49.0)$ & $23,602(66.1)$ & $18,712(54.9)$ & $21,710(43.8)$ & $15,921(38.1)$ & $14,504(65.1)$ & $16,085(55.1)$ \\
\hline Yes & $158,635(51.0)$ & $12,117(33.9)$ & $15,348(45.1)$ & $27,830(56.2)$ & $25,814(61.9)$ & $7771(34.9)$ & $13,112(44.9)$ \\
\hline \multicolumn{8}{|l|}{ Ethnicity, n (\%) } \\
\hline General & $242,022(77.8)$ & $24,232(67.8)$ & $23,486(69.0)$ & $41,613(84.0)$ & $34,218(82.0)$ & $12,456(55.9)$ & $19,899(68.2)$ \\
\hline Arab & $60,619(19.5)$ & $10,534(29.5)$ & $9884(29.0)$ & $6140(12.4)$ & $6015(14.4)$ & $9441(42.4)$ & $8599(29.5)$ \\
\hline Ultra-Orthodox & $8527(2.7)$ & $953(2.7)$ & $690(2.0)$ & $1787(3.6)$ & $1502(3.6)$ & $378(1.7)$ & $699(2.4)$ \\
\hline \multicolumn{8}{|l|}{ SES $^{\mathbf{b}}, \mathbf{n}(\%)$} \\
\hline High & $97,556(31.4)$ & $10,444(29.2)$ & $10,740(31.5)$ & $15,873(32.0)$ & $11,897(28.5)$ & $6111(27.4)$ & $7304(25.0)$ \\
\hline Medium & $126,057(40.5)$ & $12,458(34.9)$ & $11,629(34.1)$ & $22,136(44.7)$ & $18,920(45.3)$ & $6016(27.0)$ & $10,842(37.1)$ \\
\hline Low & $83,677(26.9)$ & $12,479(34.9)$ & $11,238(33.0)$ & $11,138(22.5)$ & $10,568(25.3)$ & 9669 (43.4) & $10,158(34.8)$ \\
\hline $\mathrm{N} / \mathrm{A}^{\mathrm{c}}$ & $3878(1.2)$ & $338(0.9)$ & $453(1.3)$ & $393(0.8)$ & $350(0.8)$ & $479(2.2)$ & $893(3.1)$ \\
\hline \multicolumn{8}{|l|}{ BMI, n (\%) } \\
\hline Obese & $122,984(39.5)$ & $10,395(29.1)$ & $11,453(33.6)$ & $19,181(38.7)$ & $17,280(41.4)$ & $9830(44.1)$ & $13,210(45.2)$ \\
\hline Overweight & $107,793(34.6)$ & $10,125(28.3)$ & $10,406(30.6)$ & $17,740(35.8)$ & $15,549(37.3)$ & $7845(35.2)$ & $10,355(35.5)$ \\
\hline Normal & $47,193(15.2)$ & 4635 (13.0) & $4416(13.0)$ & $7760(15.7)$ & $6748(16.2)$ & $2985(13.4)$ & $4481(15.3)$ \\
\hline Underweight & $1255(0.4)$ & $124(0.3)$ & $104(0.3)$ & $192(0.4)$ & $162(0.4)$ & $76(0.3)$ & $146(0.5)$ \\
\hline Unavailable & $31,943(10.3)$ & $10,440(29.2)$ & $7681(22.6)$ & $4667(9.4)$ & $1996(4.8)$ & $1539(6.9)$ & $1005(3.4)$ \\
\hline \multicolumn{8}{|l|}{ Smoking status, n (\%) } \\
\hline Nonsmoker & $136,815(44.0)$ & $16,116(45.1)$ & $13,359(39.2)$ & $21,896(44.2)$ & $19,062(45.7)$ & $9622(43.2)$ & $12,928(44.3)$ \\
\hline Past smoker & $67,300(21.6)$ & 6294 (17.6) & $6249(18.3)$ & $10,050(20.3)$ & $8434(20.2)$ & $5061(22.7)$ & $6481(22.2)$ \\
\hline Current smoker & $43,190(13.9)$ & $7064(19.8)$ & $4259(12.5)$ & 7649 (15.4) & $5546(13.3)$ & $2959(13.3)$ & 3765 (12.9) \\
\hline Unavailable & $63,863(20.5)$ & $6245(17.5)$ & $10,193(29.9)$ & $9945(20.1)$ & $8693(20.8)$ & $4633(20.8)$ & $6023(20.6)$ \\
\hline $\mathrm{ACG}^{\mathrm{d}}$, median (IQR) & $4(3-5)$ & $3(2-4)$ & $3(3-4)$ & $4(3-4)$ & $4(4-5)$ & $4(4-5)$ & $4(4-5)$ \\
\hline \multicolumn{8}{|l|}{$\mathrm{HbA}_{1 \mathrm{c}}{ }^{\mathrm{e}}(\mathrm{mmol} / \mathrm{mol})$} \\
\hline $\mathrm{n}(\%)$ & $27,3491(87.9)$ & $22,748(63.3)$ & $27,951(82.1)$ & $43,651(88.1)$ & $39,015(93.5)$ & 20,687 (92.9) & $23,249(93.3)$ \\
\hline Mean (SD) & $7.19(1.46)$ & $7.31(1.73)$ & $7.16(1.39)$ & $7.22(1.47)$ & $7.15(1.41)$ & $7.22(1.45)$ & $7.39(1.57)$ \\
\hline \multicolumn{8}{|l|}{ Cholesterol (mg/dL) } \\
\hline $\mathrm{n}(\%)$ & $282,583(90.8)$ & $24,541(68.7)$ & 29,139 (85.6) & $45,069(91.0)$ & $40,035(95.9)$ & $21,306(95.6)$ & $27,832(95.3)$ \\
\hline Mean (SD) & $167.78(41.08)$ & $186.01(43.7)$ & $167.41(39.5)$ & $169.09(40.8)$ & $167.25(40.05)$ & $166.54(40.01)$ & $164.40(40.47)$ \\
\hline \multicolumn{8}{|l|}{ Adherence, n (\%) } \\
\hline Not treated & $65,873(21.2)$ & $14,213(39.8)$ & $7078(20.8)$ & $9126(18.4)$ & $7246(17.4)$ & 4004 (18.0) & $5475(18.8)$ \\
\hline $0 \%$ & $10,501(3.4)$ & $2601(7.3)$ & $729(2.1)$ & $1731(3.5)$ & $1254(3.0)$ & $710(3.2)$ & $792(2.7)$ \\
\hline
\end{tabular}




\begin{tabular}{|c|c|c|c|c|c|c|c|}
\hline \multirow[t]{2}{*}{ Characteristic } & \multirow{2}{*}{$\begin{array}{l}\text { Overall } \\
(n=311,168)\end{array}$} & \multicolumn{2}{|c|}{ Relatively low contacts } & \multicolumn{2}{|c|}{ Low and scheduled visits } & \multicolumn{2}{|c|}{ Measured human contacts } \\
\hline & & $\begin{array}{l}\text { Tech-based } \\
(n=35,719)\end{array}$ & $\begin{array}{l}\text { Non-clinic- } \\
\text { based } \\
(n=34,060)\end{array}$ & $\begin{array}{l}\text { Moderate nonvis- } \\
\text { iting services } \\
(\mathrm{n}=49,540)\end{array}$ & $\begin{array}{l}\text { Low balance } \\
\text { use }(n=41,735)\end{array}$ & $\begin{array}{l}\text { Nonplanners } \\
(\mathrm{n}=22,275)\end{array}$ & $\begin{array}{l}\text { Nursing-based } \\
\text { contacts } \\
(n=29,197)\end{array}$ \\
\hline $1 \%-19 \%$ & $11,990(3.9)$ & $2141(6.0)$ & $804(2.4)$ & $1794(3.6)$ & $1691(4.1)$ & $1034(4.6)$ & $1229(4.2)$ \\
\hline $20 \%-39 \%$ & $17,573(5.6)$ & $3195(8.9)$ & $1312(3.9)$ & 2903 (5.9) & $2497(6.0)$ & $1350(6.1)$ & $1583(5.4)$ \\
\hline $40 \%-59 \%$ & 27,107 (8.7) & $3502(9.8)$ & $2538(7.5)$ & $4823(9.7)$ & 3987 (9.6) & 1907 (8.6) & $2411(8.3)$ \\
\hline $60 \%-79 \%$ & $31,447(10.1)$ & 3104 (8.7) & 3168 (9.3) & $5350(10.8)$ & $4690(11.2)$ & $2236(10.0)$ & $3031(10.4)$ \\
\hline$\geq 80 \%$ & $146,677(47.1)$ & 6963 (19.5) & $18,431(54.1)$ & $23,813(48.1)$ & $20,370(48.8)$ & $11,034(49.5)$ & $14,676(50.3)$ \\
\hline
\end{tabular}

${ }^{\mathrm{a}} \mathrm{IQR}$ : interquartile range.

${ }^{\mathrm{b}} \mathrm{SES}$ : socioeconomic status.

${ }^{\mathrm{c}} \mathrm{N} / \mathrm{A}$ : not applicable.

${ }^{\mathrm{d}}$ ACG: adjusted clinical group.

${ }^{\mathrm{e}} \mathrm{HbA}_{1 \mathrm{c}}$ : glycated hemoglobin. 
Table 3. Sociodemographic, clinical, and biological measurements data summary for patients with diabetes who had a moderate-to-high health care services consumption in 2016 .

\begin{tabular}{|c|c|c|c|c|c|c|c|c|}
\hline \multirow[t]{2}{*}{ Characteristic } & \multirow{2}{*}{$\begin{array}{l}\text { Overall } \\
(\mathrm{n}=311,168)\end{array}$} & \multicolumn{2}{|c|}{ High electronic contacts } & \multirow{2}{*}{$\begin{array}{l}\text { Automated in- } \\
\text { teraction early } \\
\text { adopters } \\
(n=26,290)\end{array}$} & \multicolumn{2}{|c|}{ Human-based contacts } & \multirow{2}{*}{$\begin{array}{l}\text { Overall } \\
\text { high con- } \\
\text { tact } \\
(\mathrm{n}=9736)\end{array}$} & \multirow{2}{*}{$\begin{array}{l}\text { Electronic } \\
\text { driven inter- } \\
\text { action } \\
(\mathrm{n}=14,647)\end{array}$} \\
\hline & & $\begin{array}{l}\text { Internet web- } \\
\text { site } \\
(n=19,277)\end{array}$ & $\begin{array}{l}\text { Smartphone } \\
(n=13,279)\end{array}$ & & $\begin{array}{l}\text { Nursing-cen- } \\
\text { tered } \\
(\mathrm{n}=7276)\end{array}$ & $\begin{array}{l}\text { Physician- } \\
\text { centered } \\
(\mathrm{n}=8137)\end{array}$ & & \\
\hline \multicolumn{9}{|l|}{ Gender, n (\%) } \\
\hline Female & $156,269(50.2)$ & $8652(44.9)$ & $7250(54.6)$ & $15,034(57.2)$ & $3939(54.1)$ & 3815 (46.9) & $4649(47.8)$ & $6227(42.5)$ \\
\hline Male & $154,899(49.8)$ & $10,625(55.1)$ & $6029(45.4)$ & $11,256(42.8)$ & 3337 (45.9) & $4322(53.1)$ & $5087(52.2)$ & $8420(57.5)$ \\
\hline $\begin{array}{l}\text { Age in years, median } \\
\left(\mathrm{IQR}^{\mathrm{a}}\right)\end{array}$ & $68(60-77)$ & $68(61-75)$ & $64(56-72)$ & $72(65-79)$ & $70(61-79)$ & $73(65-81)$ & $71(65-79)$ & $65(59-71)$ \\
\hline \multicolumn{9}{|l|}{ Immigrant, n (\%) } \\
\hline No & $152,533(49.0)$ & $8499(44.1)$ & $6645(50.0)$ & $9489(36.1)$ & $3230(44.4)$ & 3349 (41.2) & $3556(36.5)$ & $7231(50.6)$ \\
\hline Yes & $158,635(51.0)$ & $10,778(55.9)$ & $6634(50.0)$ & $16,801(63.9)$ & $4046(55.6)$ & $4788(58.8)$ & $6180(63.5)$ & $7416(50.6)$ \\
\hline \multicolumn{9}{|l|}{ Ethnicity, n (\%) } \\
\hline General & $242,022(77.8)$ & $18,498(96.0)$ & $10,977(82.7)$ & $21,399(81.4)$ & $5745(79.0)$ & $6255(76.9)$ & $9241(94.9)$ & $\begin{array}{l}14,003 \\
(95.6)\end{array}$ \\
\hline Arab & $60,619(19.5)$ & $478(2.5)$ & 2105 (15.9) & $3895(14.8)$ & $1311(18.0)$ & $1656(20.4)$ & $313(3.2)$ & $248(1.7)$ \\
\hline Ultra-Orthodox & $8527(2.7)$ & $301(1.6)$ & $197(1.5)$ & $996(3.8)$ & $220(3.0)$ & $226(2.8)$ & $182(1.9)$ & $396(2.7)$ \\
\hline \multicolumn{9}{|l|}{ SES $^{\mathbf{b}}, \mathbf{n}(\%)$} \\
\hline High & $97,556(31.4)$ & $9961(51.7)$ & $3625(27.3)$ & 7079 (26.9) & $1895(26.0)$ & $2101(25.8)$ & 4535 (46.6) & $5991(40.9)$ \\
\hline Medium & $126,057(40.5)$ & $7729(40.1)$ & $5981(45.0)$ & $12,231(46.5)$ & $3292(45.2)$ & $3525(43.3)$ & 4275 (43.9) & $7023(47.9)$ \\
\hline Low & 83,677 (26.9) & $1430(7.4)$ & $3511(26.4)$ & $6683(25.4)$ & $2041(28.1)$ & 2417 (29.7) & $842(8.6)$ & $1503(10.3)$ \\
\hline$N / A^{c}$ & $3878(1.2)$ & $157(0.8)$ & $162(1.2)$ & $297(1.1)$ & $48(0.7)$ & $94(1.2)$ & $84(0.9)$ & $130(0.9)$ \\
\hline \multicolumn{9}{|l|}{ BMI, n (\%) } \\
\hline Obese & $122,984(39.5)$ & $7421(38.5)$ & $6174(46.5)$ & $12,154(46.2)$ & $3128(43.0)$ & $3336(41.0)$ & $4071(41.8)$ & $5351(36.5)$ \\
\hline Overweight & $107,793(34.6)$ & 7299 (37.9) & $4512(34.0)$ & $9374(35.7)$ & 2514 (34.6) & $2800(34.4)$ & $3749(38.5)$ & $5525(37.7)$ \\
\hline Normal & $47,193(15.2)$ & $3123(16.2)$ & $1819(13.7)$ & $4316(16.4)$ & $1307(18.0)$ & $1621(19.9)$ & $1666(17.1)$ & $2316(15.8)$ \\
\hline Underweight & $1255(0.4)$ & $48(0.2)$ & $53(0.4)$ & $112(0.4)$ & $55(0.8)$ & $97(1.2)$ & $42(0.4)$ & $44(0.3)$ \\
\hline Unavailable & $31,943(10.3)$ & $1386(7.2)$ & $721(5.4)$ & $334(1.3)$ & $272(3.7)$ & $283(3.5)$ & $208(2.1)$ & $1411(9.6)$ \\
\hline \multicolumn{9}{|l|}{ Smoking status, n (\%) } \\
\hline Nonsmoker & $136,815(44.0)$ & 8769 (45.5) & $6669(50.2)$ & $11,955(45.5)$ & $3034(41.7)$ & $2951(36.3)$ & $4131(42.4)$ & $6323(43.2)$ \\
\hline Past smoker & $67,300(21.6)$ & $5127(26.6)$ & $3086(23.2)$ & $5904(22.5)$ & $1582(21.7)$ & $2119(26.0)$ & $2835(29.1)$ & $4078(27.8)$ \\
\hline Current smoker & 43,190 (13.9) & $1862(9.7)$ & $1813(13.7)$ & 2799 (10.6) & $1191(16.4)$ & $1087(13.4)$ & $756(7.8)$ & $2440(16.7)$ \\
\hline Unavailable & $63,863(20.5)$ & $3519(18.3)$ & $1711(12.9)$ & $5632(21.4)$ & $1469(20.2)$ & $1980(24.3)$ & $2014(20.7)$ & $1806(12.3)$ \\
\hline $\mathrm{ACG}^{\mathrm{d}}$, median (IQR) & $4(3-5)$ & $4(3-5)$ & $4(4-5)$ & $5(4-5)$ & $5(4-5)$ & $5(5-6)$ & $5(4-5)$ & $4(3-5)$ \\
\hline \multicolumn{9}{|l|}{$\mathrm{HbA}_{1 \mathrm{c}}{ }^{\mathrm{e}},(\mathrm{mmol} / \mathrm{mol})$} \\
\hline $\mathrm{n}(\%)$ & $273,491(87.9)$ & $17,810(92.4)$ & $12,387(93.3)$ & $25,320(96.3)$ & $6769(93.0)$ & 7594 (93.3) & $9373(96.3)$ & $\begin{array}{l}12,936 \\
(88.3)\end{array}$ \\
\hline Mean (SD) & $7.19(1.46)$ & $6.86(1.13)$ & $7.19(1.46)$ & $7.22(1.42)$ & $7.24(1.57)$ & $7.26(1.60)$ & $6.91(1.17)$ & $7.15(1.37)$ \\
\hline \multicolumn{9}{|l|}{ Cholesterol (mg/dL) } \\
\hline $\mathrm{n}(\%)$ & $282,583(90.8)$ & $18,399(95.4)$ & $12,713(96.0)$ & $25,849(98.3)$ & $6973(95.8)$ & $7875(96.8)$ & $9586(98.5)$ & $\begin{array}{l}13,232 \\
(80.3)\end{array}$ \\
\hline
\end{tabular}




\begin{tabular}{|c|c|c|c|c|c|c|c|c|}
\hline \multirow[t]{2}{*}{ Characteristic } & \multirow{2}{*}{$\begin{array}{l}\text { Overall } \\
(\mathrm{n}=311,168)\end{array}$} & \multicolumn{2}{|c|}{ High electronic contacts } & \multirow{2}{*}{$\begin{array}{l}\text { Automated in- } \\
\text { teraction early } \\
\text { adopters } \\
(n=26,290)\end{array}$} & \multicolumn{2}{|c|}{ Human-based contacts } & \multirow{2}{*}{$\begin{array}{l}\text { Overall } \\
\text { high con- } \\
\text { tact } \\
(\mathrm{n}=9736)\end{array}$} & \multirow{2}{*}{$\begin{array}{l}\text { Electronic } \\
\text { driven inter- } \\
\text { action } \\
(\mathrm{n}=14,647)\end{array}$} \\
\hline & & $\begin{array}{l}\text { Internet web- } \\
\text { site } \\
(\mathrm{n}=19,277)\end{array}$ & $\begin{array}{l}\text { Smartphone } \\
(\mathrm{n}=13,279)\end{array}$ & & $\begin{array}{l}\text { Nursing-cen- } \\
\text { tered } \\
(\mathrm{n}=7276)\end{array}$ & $\begin{array}{l}\text { Physician- } \\
\text { centered } \\
(\mathrm{n}=8137)\end{array}$ & & \\
\hline Mean (SD) & $167.78(41.08)$ & $165.51(39.4)$ & $166.77(40.54)$ & $161.96(39.28)$ & $\begin{array}{l}169.36 \\
(44.28)\end{array}$ & $\begin{array}{l}159.30 \\
(44.77)\end{array}$ & $\begin{array}{l}160.79 \\
(39.47)\end{array}$ & $\begin{array}{l}165.85 \\
(40.10)\end{array}$ \\
\hline \multicolumn{9}{|c|}{ Adherence, n (\%) } \\
\hline Not treated & $65,873(21.2)$ & $4020(20.9)$ & $2487(18.7)$ & $4278(16.3)$ & $1552(21.3)$ & $2094(25.7)$ & $1889(19.4)$ & $2411(16.5)$ \\
\hline $0 \%$ & $10,501(3.4)$ & $503(2.6)$ & $448(3.4)$ & $617(2.3)$ & $245(3.4)$ & $253(3.1)$ & $239(2.5)$ & $379(2.6)$ \\
\hline $1 \%-19 \%$ & $11,990(3.9)$ & $458(2.4)$ & $548(4.1)$ & $941(3.6)$ & $357(4.9)$ & $341(4.2)$ & $269(2.8)$ & $383(2.6)$ \\
\hline $20 \%-39 \%$ & $17,573(5.6)$ & $723(3.8)$ & $823(6.2)$ & $1346(5.1)$ & $489(6.7)$ & $462(5.7)$ & $346(3.6)$ & $544(3.7)$ \\
\hline $40 \%-59 \%$ & 27,107 (8.7) & $1325(6.9)$ & $1234(9.3)$ & $2156(8.2)$ & $697(9.6)$ & $741(9.1)$ & $560(5.8)$ & $1226(8.4)$ \\
\hline $60 \%-79 \%$ & $31,447(10.1)$ & $1711(8.9)$ & $1447(10.9)$ & $2712(10.3)$ & 849 (11.7) & $819(10.1)$ & $804(8.3)$ & $1526(10.4)$ \\
\hline$\geq 80 \%$ & $146,677(47.1)$ & $10,537(54.7)$ & $6292(47.4)$ & $14,240(54.2)$ & $3087(42.4)$ & $3427(42.1)$ & $5629(57.8)$ & $8178(55.8)$ \\
\hline
\end{tabular}

${ }^{\mathrm{a}} \mathrm{IQR}$ : interquartile range.

${ }^{b}$ SES: socioeconomic status.

${ }^{\mathrm{c}} \mathrm{N} / \mathrm{A}$ : not applicable.

${ }^{\mathrm{d}} \mathrm{ACG}$ : adjusted clinical group.

${ }^{\mathrm{e}} \mathrm{HbA}_{1 \mathrm{c}}$ : glycated hemoglobin.

Figures 3-6 show charts comparing the differences between the low-to-moderate and moderate-to-high health care services consumer clusters.

Figure 3 shows the differences in health care services use:

- Administrative contacts relate to scheduling an appointment or submitting a nonqueue request (NQR) by a face-to-face meeting at clinic or call to clinic or call center

- Health care practitioner contacts in community relate to physician and nurse consultations and overall visits to pharmacies

- Service consumption at hospital relates to hospitalization and visits to emergency departments

- New communication channels relate to scheduling an appointment or submitting an NQR by using the HMO internet website or smartphone app or answering an SMS suggesting a prescription renewal

Low-to-moderate health care services customers use more administrative contacts than moderate-to-high patients, who use more of the other communication methods.

Figure 4 depicts sociodemographic data. The differences in age and gender are relatively small. There is a higher representation of females in the low-to-moderate cluster, and its patients are slightly younger. More profound differences are at the socioeconomic status (SES) and religious sector. In the low-to-moderate group, there is a higher representation of patients with medium SES, and it has a higher representation of patients from the Arab sector. The moderate-to-high cluster comprises patients with low and high SES mainly from the general (Jewish sector) and immigrant sectors.

Figure 5 compares bioclinical follow-up quality. Generally, the follow-up quality is better in the moderate-to-high cluster than in the low-to-moderate one.

Figure 6 relates to adherence to treatment. A higher proportion of patients from the low-to-moderate cluster are not treated for diabetes, and the adherence of the ones who are treated is much lower than patients in the moderate-to-high cluster. 
Figure 3. Low-to-moderate versus moderate-to-high health care services consumption of patients with diabetes in 2016.

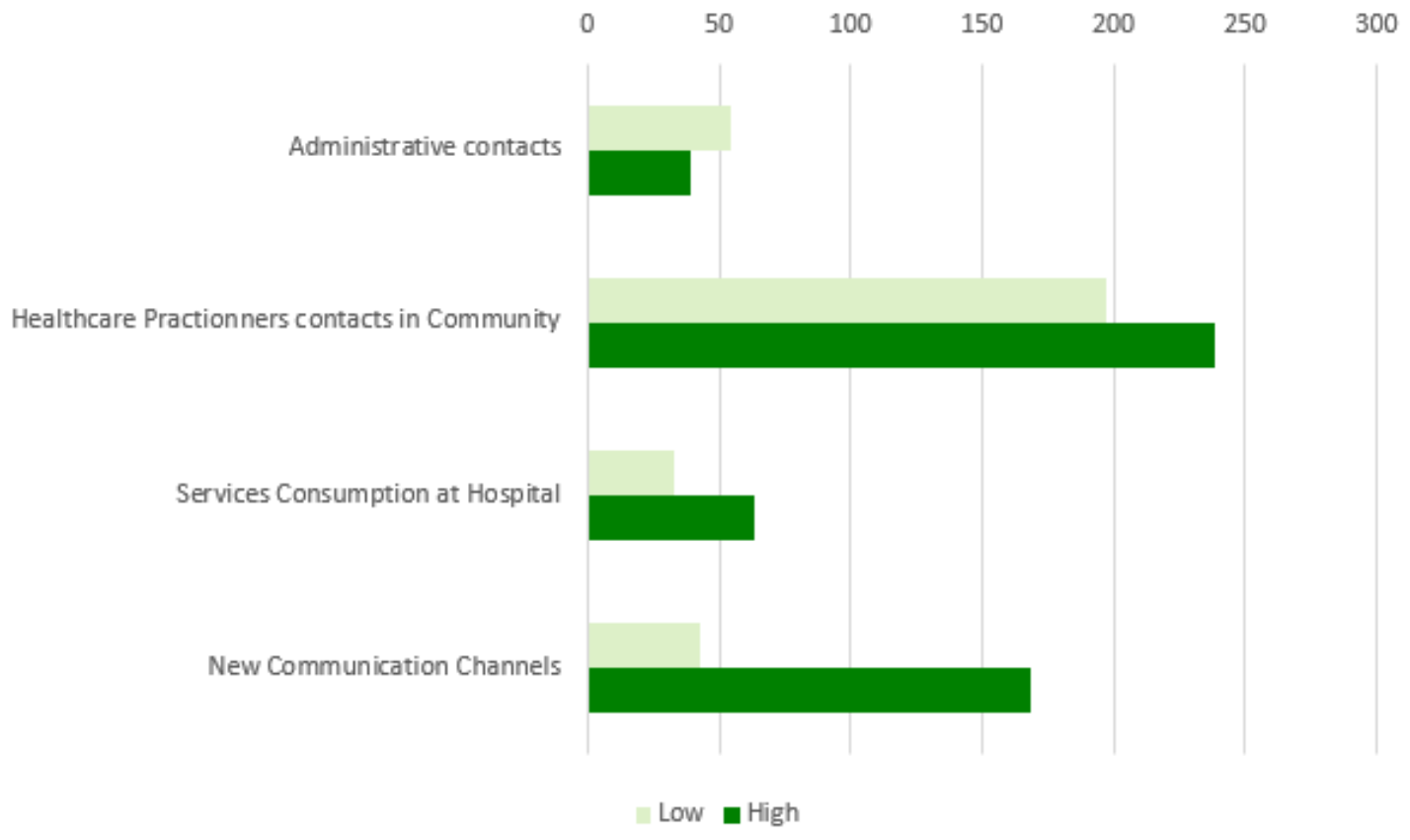

Figure 4. Differences in sociodemographic attributes between low-to-moderate and moderate-to-high health care services consumption of patients with diabetes in 2016. SES: socioeconomic status.

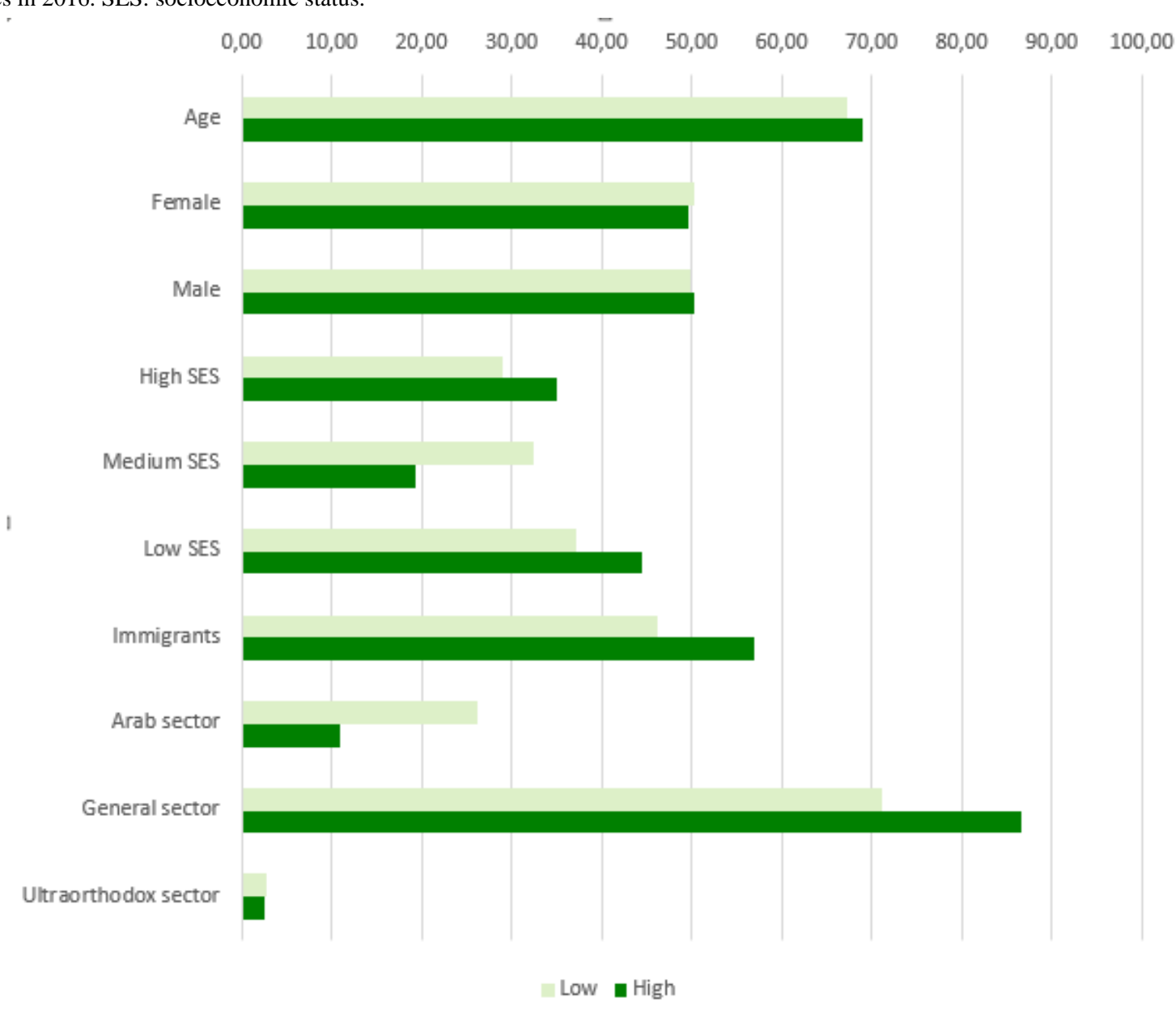


Figure 5. Differences of bioclinical follow-up quality between low-to-moderate and moderate-to-high health care services consumption of patients with diabetes in 2016. HbA1c: glycated hemoglobin.

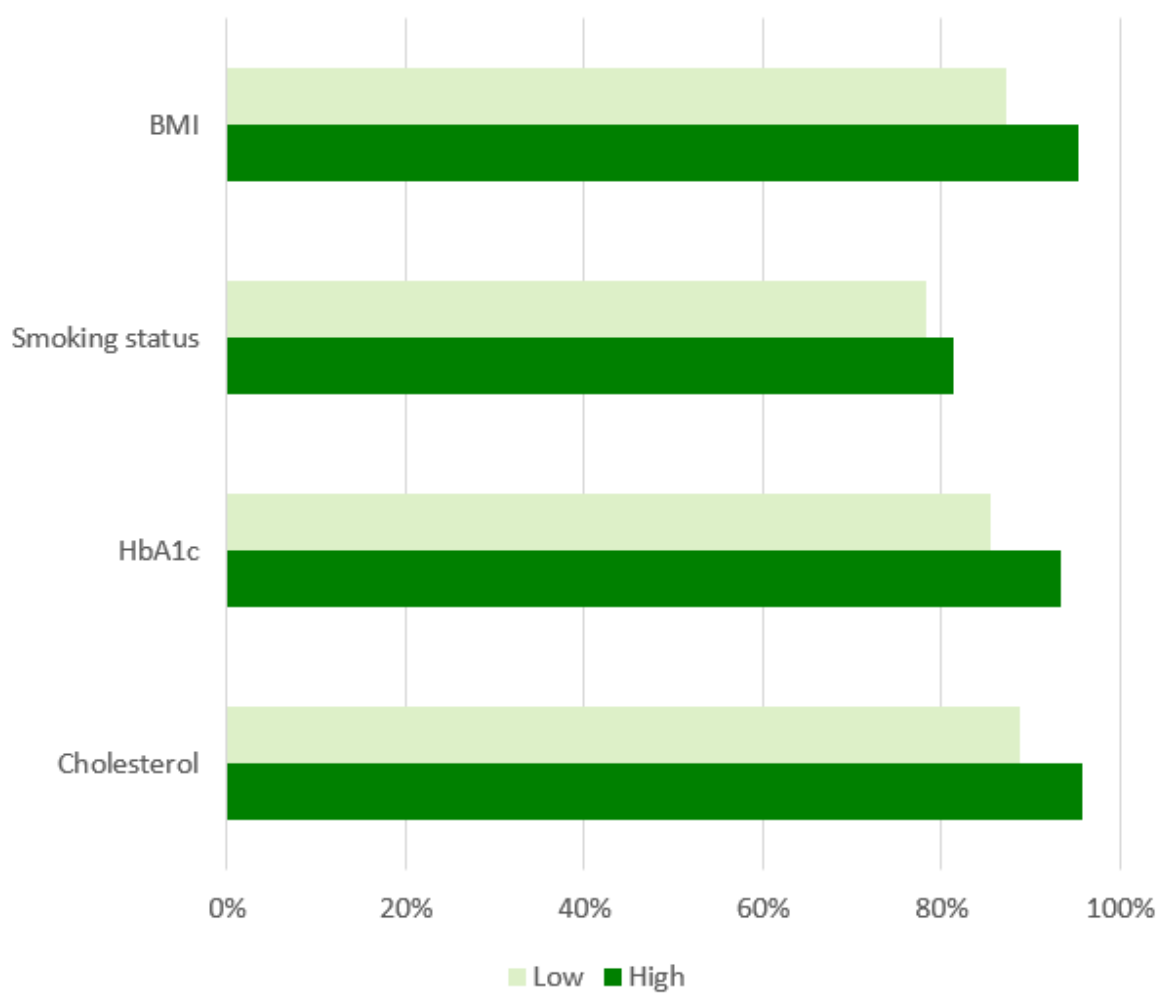

Figure 6. Differences of adherence to treatment between low-to-moderate and moderate-to-high health care services consumption of patients with diabetes in 2016.

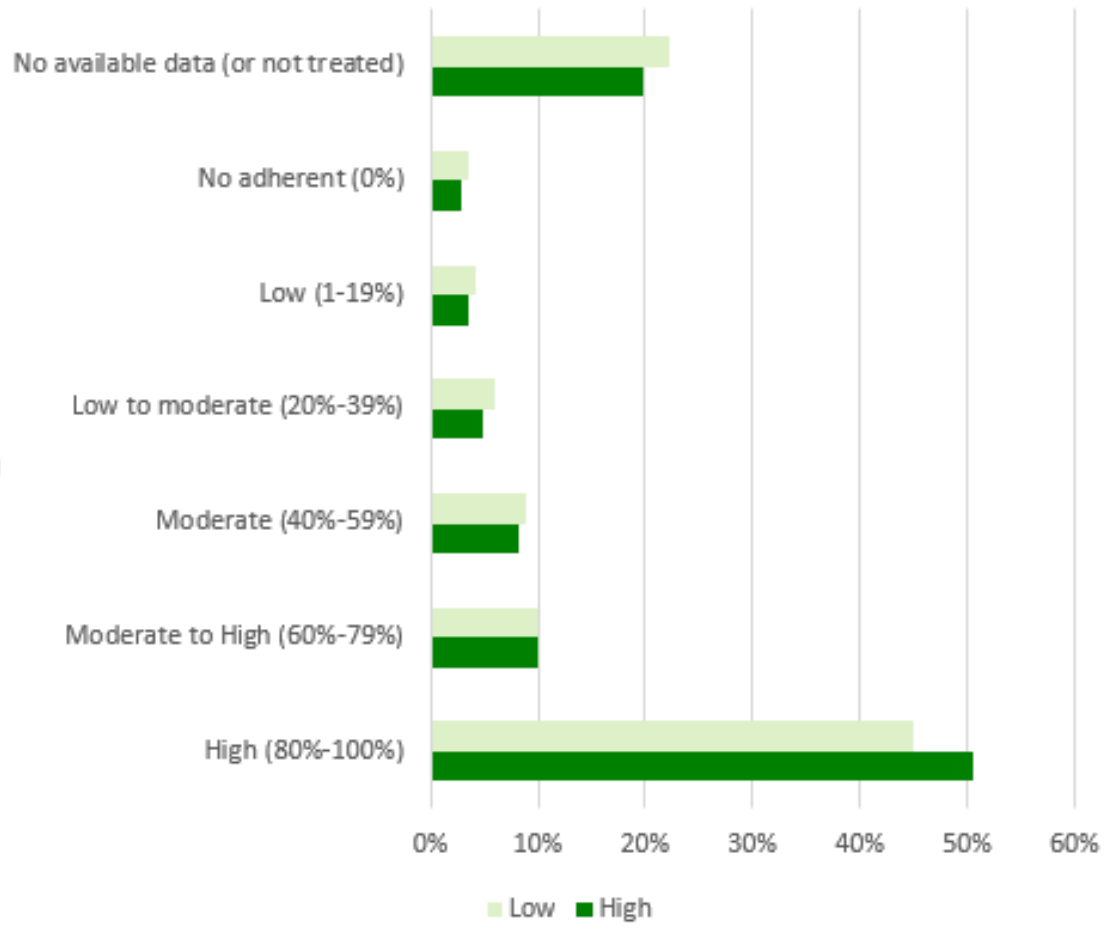

Generally, low-to-moderate health care services customers tend to prefer direct contacts with health care professionals, and this is probably the cause for lower follow-up quality and adherence to treatment. Conversely, patients in the moderate-to-high Below we describe the 13 communication profiles found in 2016 and characterize them based on sociodemographic and bioclinical data available. Keeping the population of each one clusters use myriad communication channels. constant, we describe how the communication behavior has 
changed from 2009 to 2016 as health care professionals introduced new technological means of communications.

\section{Low-to-Moderate Health Care Services Customers}

\section{Relatively Low Contact}

\section{Tech-Based}

This cluster includes $11.48 \%(35,719 / 311,168)$ of the cohort. Patients in this group use fewer physical interactions and tend to be early adopters of new channels (Table 2 and Figure 7). They exhibit a relatively high use of electronic channels for scheduling appointments and online NQR tools when these channels became available. They are relatively young, men are highly represented $(20,039 / 35,719,56.10 \%)$, as are the Arab sector $(10,537 / 35,719,29.49 \%)$ and low SES population $(12,479 / 35,719,34.93 \%)$. Their follow-up quality is relatively poor but progressively improving. The missing measurements of BMI (2008: $37.30 \% \quad[13,323 / 35,719] ; 2016: 29.20 \%$ [10,430/35,719]) and $\mathrm{HbA}_{1 \mathrm{c}}$ (2008: 56.30\% [20,110/35,719]; 2016: $36.30 \%$ [12,966/35,719]) decreased over time. Despite the aging, the $\mathrm{HbA}_{1 \mathrm{c}}$ average increased just a little (7.06 [SD 1.58 ] $\mathrm{mmol} / \mathrm{mol}$ vs 7.31 [SD 1.7] $\mathrm{mmol} / \mathrm{mol}$ ). Of patients who were followed up, the percentage of patients treated for diabetes increased (2009: 32.8\% [11,716/35,719]; 2016: 60.20\% $[21,503 / 35,719])$, as did the proportion of highly adherent patients (2009: 13.40\% [4786/35,719], 2016: $19.50 \%$ [6965/35,719]), with significant changes in 2011 and 2012 when NQRs and online (website and smartphone app) appointment scheduling were introduced. This group also started using the SMS channel for renewing prescriptions in 2015 when this channel was launched.

Figure 7. Communication pattern changes between 2008 and 2016 for the relatively low contacts — tech-based group.

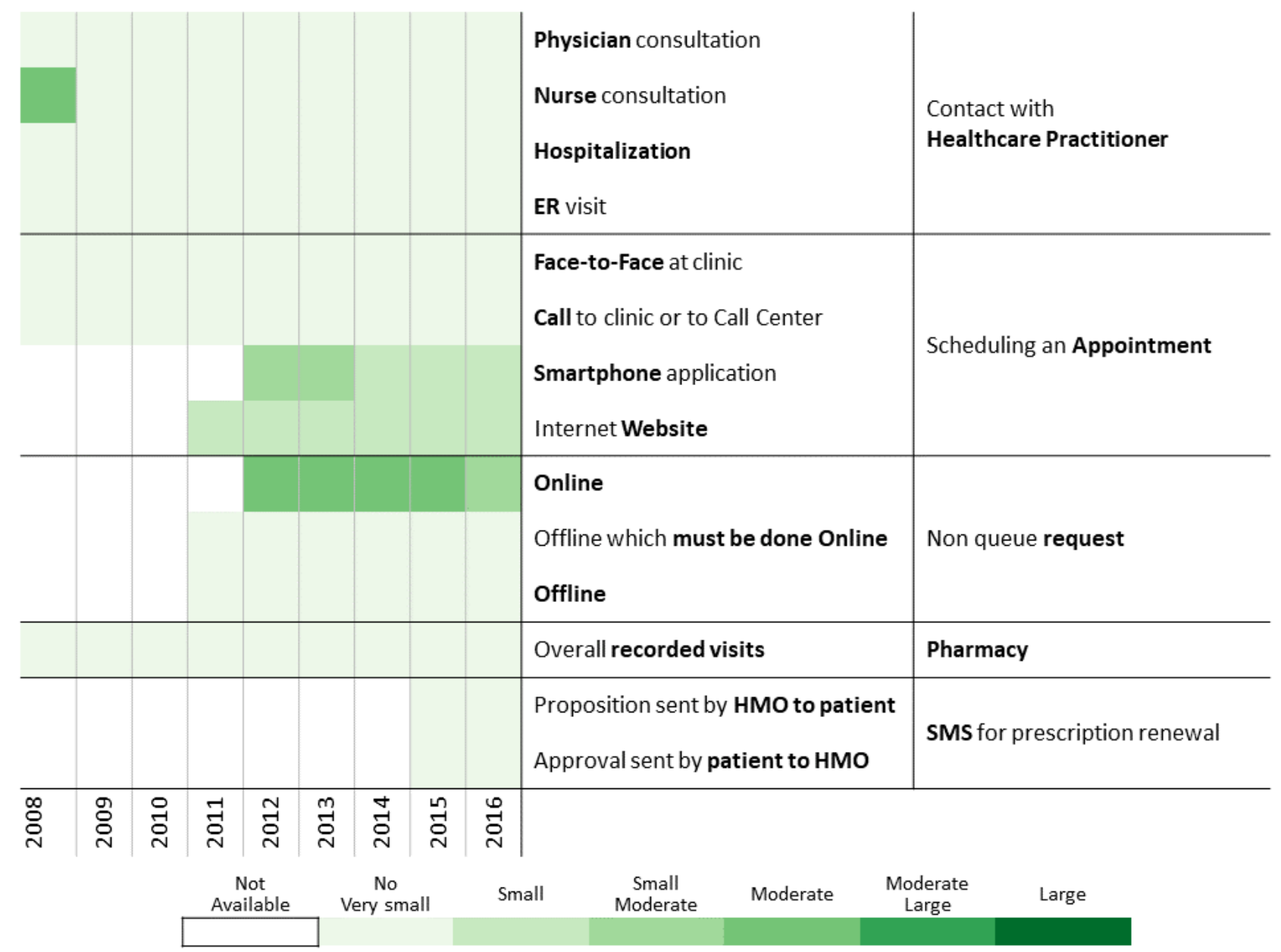

\section{Non-Clinic-Based}

This cluster includes $10.95 \%$ of the cohort $(34,060 / 311,168$; Figure 8). Its median age is similar to the cohort, and the Arab sector is highly represented (9884/34,060, 29.02\%). Until 2011, communication between patients and health care professionals was mainly achieved directly with the health care professionals. When electronic channels became available that year, the proportion of visits to health care professionals decreased in favor of online NQRs. The proportion of missing follow-up measurements is stable at around $20 \%$ each year. $\mathrm{HbA}_{1 \mathrm{c}}$ values are also relatively stable over time $(7.16$ [SD 1.39$] \mathrm{mmol} / \mathrm{mol}$ in 2016). The percentage of patients treated for diabetes increased (2009: 56.50\% [19,244/34,060]; 2016: 78.20\% $[26,635 / 34,060])$ and is associated with an increase in high proportion of days covered (2009: $36.01 \%$ [12,266/34,060]; 2016: $54.11 \%[18,431 / 34,060])$. This improvement in adherence over time is correlated with the use of the different electronic nonclinic contacts. 
Figure 8. Communication pattern changes between 2008 and 2016 for the relatively low contacts — non-clinic-based group.

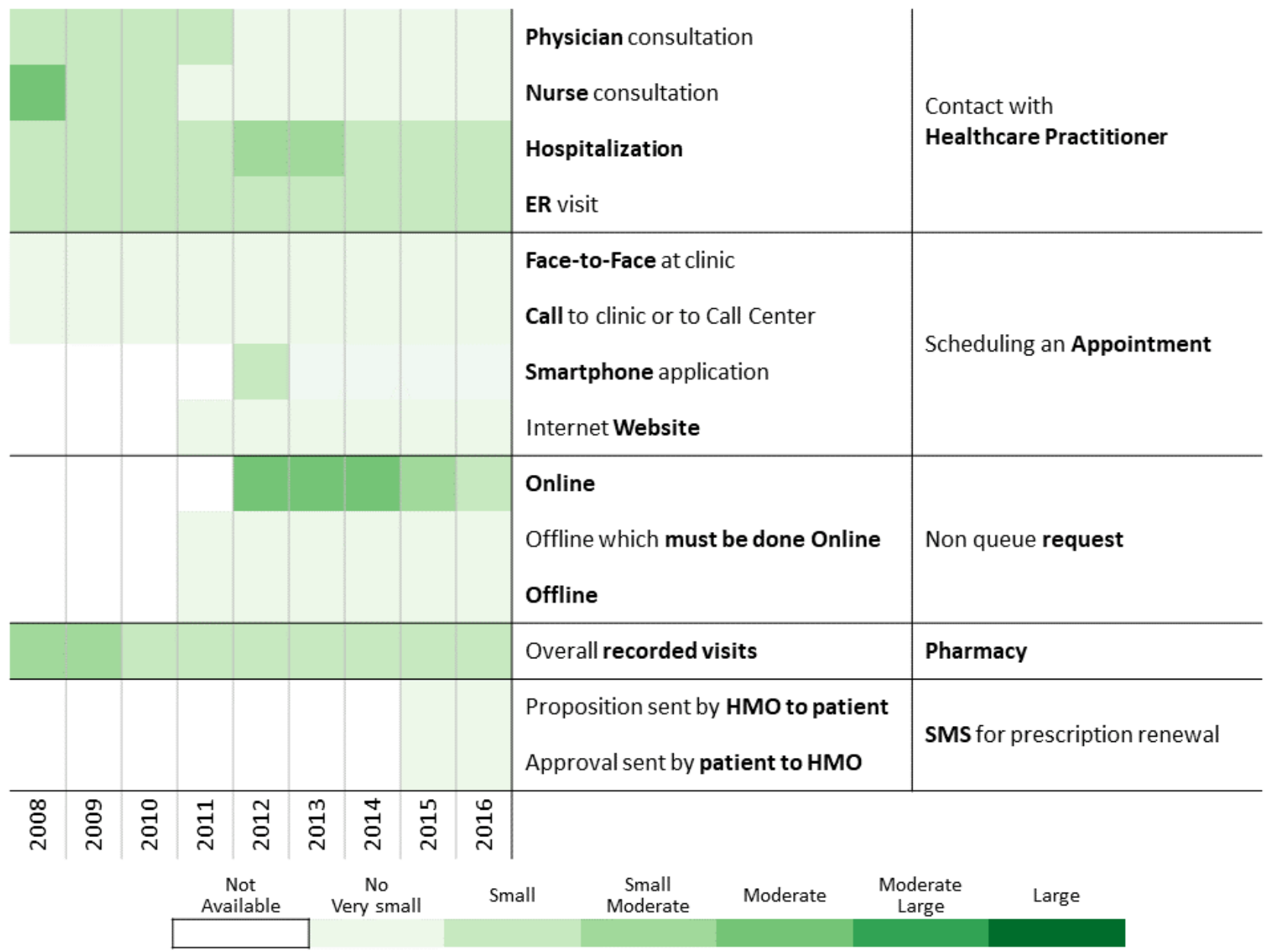

\section{Tech-Based Versus Non-Clinic-Based}

Analyzing the relatively low contact groups over time reveals that while the tech-based group prefers technology-based means of communication, the non-clinic-based group has a relatively high number of hospitalizations and visits to the emergency department compared with the rest of the population.

While the introduction of new digital communication channels is correlated with an increase in adherence to treatment for the tech-based group, patients in the non-clinic-based group do not exhibit this kind of behavior. On the contrary, there is a correlation between the introduction of new communication channels and a reduction in the average number of physician visits. For the tech-based cluster, the introduction of new communication channels might be viewed as an opportunity to decrease the number of contacts with the HMO.

\section{Low and Scheduled Visits}

\section{Moderate Nonvisits}

This group, which includes $15.92 \%(49,540 / 311,168)$ of the cohort, comprises patients who mainly use communication channels that do not involve face-to-face consultations (Table 2 and Figure 9). Its median age is close to the cohort median age of 67 years, and the general sector is highly represented $(41,613 / 49,540,84.00 \%)$. Until 2011 when the first electronic channels were introduced, patients in this group resorted to the available communication channels apart from physicians such as consulting nurses, hospitalizations, and emergency department visits. Once electronic options were introduced, the volume of contacts with health care professionals decreased in favor of the online tools for scheduling appointments and NQRs. Furthermore, this group was proactive and had a high answering rate to the SMS for automated prescription renewal. The proportion of patients taking a medication for diabetes jumped from $51.40 \%(25,464 / 49,540)$ in 2009 to $81.60 \%$ $(40,425 / 49,540)$ in 2016 . These values are associated with a high adherence to treatment, which increased by $17.70 \%$ between 2009 and 2016. Even though these patients consulted health care professionals less often, the proportion of missing annual measurements of follow-up metrics dropped from more than $20 \%$ in 2008 to approximatively $10 \%$ in 2016 . For this subpopulation, additional channels are an opportunity to adjust communication patterns with the HMO to their preferences. 
Figure 9. Communication patterns for patients having a low number but scheduled visits and preferring communication channels that do not involve a face-to-face meeting.

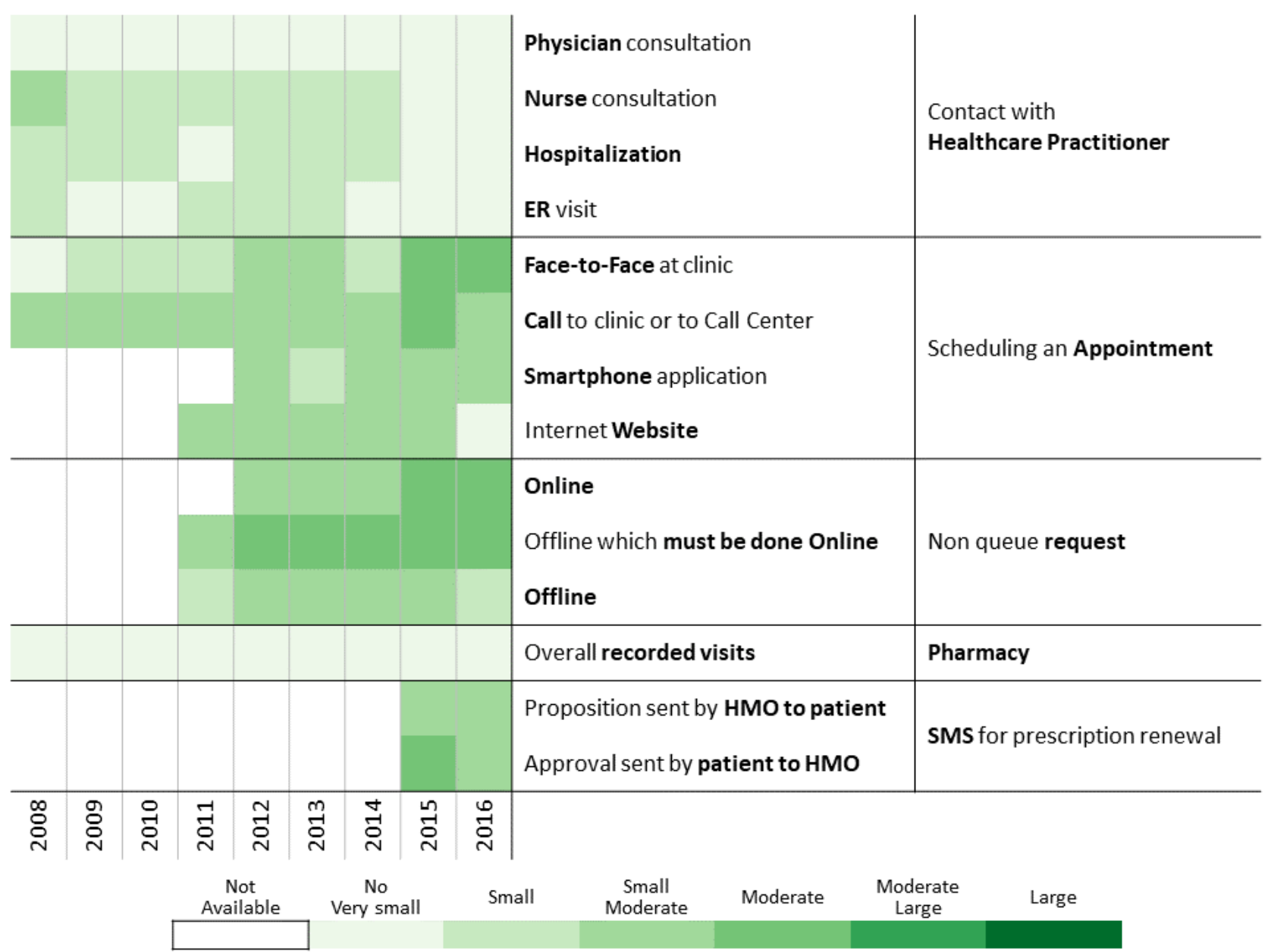

\section{Low Balance Use}

This cluster includes $13.41 \%(41,735 / 311,168)$ of the cohort (Table 2 and Figure 10). These patients are using all available services at a relatively low rate. The cluster median age is higher than the cohort, and there is a higher proportion of immigrants. Despite the diversity of available and newly introduced communication channels, health care services consumption is stable. These patients prefer traditional channels for appointment scheduling (ie, face-to-face at clinic, call to clinic or call center). Adding technology-based channels has a marginal effect on communication with health care professionals. Clinically, adjusted clinical group (ACG) level remains relatively stable over time (2010: 4 [3;4]; 2016: 4 [4;5]), and $\mathrm{HbA}_{1 \mathrm{c}}$ level is globally controlled (2016: 7.15 [SD 1.41] mmol/mol). Despite low use of available channels, patients have high rates of adherence to follow-up and treatment that increase over time. The proportion of missing annual measurements of follow-up metrics dropped (2008: around 15\%; 2016: around 7\%), and the percentage of patients with high adherence increased. This change may be attributed to aging and changes in therapeutic status (patients taking a noninsulin medication for diabetes jumped from $51.40 \%$ [25,464/49,540] in 2009 to $81.60 \%$ $[40,425 / 49,540]$ in 2016). 
Figure 10. Communication patterns for patients with diabetes having low balance use of health care services and scheduled visits.

\begin{tabular}{|c|c|c|c|c|c|c|c|c|c|c|}
\hline & & & & & & & & & $\begin{array}{l}\text { Physician consultation } \\
\text { Nurse consultation } \\
\text { Hospitalization } \\
\text { ER visit }\end{array}$ & $\begin{array}{l}\text { Contact with } \\
\text { Healthcare Practitioner }\end{array}$ \\
\hline & & & & & & & & & $\begin{array}{l}\text { Face-to-Face at clinic } \\
\text { Call to clinic or to Call Center } \\
\text { Smartphone application } \\
\text { Internet Website }\end{array}$ & 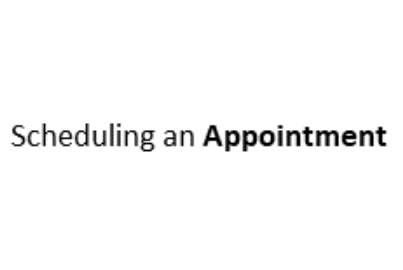 \\
\hline & & & & & & & & & $\begin{array}{l}\text { Online } \\
\text { Offline which must be done Online } \\
\text { Offline }\end{array}$ & Non queue request \\
\hline & & & & & & & & & $\begin{array}{l}\text { Overall recorded visits } \\
\text { Proposition sent by HMO to patient } \\
\text { Approval sent by patient to HMO }\end{array}$ & $\begin{array}{l}\text { Pharmacy } \\
\text { SMS for prescription renewal }\end{array}$ \\
\hline$\stackrel{\infty}{\circ}$ & 용 & $\stackrel{\circ}{\circ}$ & 공 & $\stackrel{\sim}{\stackrel{ }{*}}$ & $\stackrel{m}{\stackrel{n}{\circ}}$ & $\mid \begin{array}{c}\stackrel{+}{\mathcal{O}} \\
\text { No } \\
\text { Nery small }\end{array}$ & $\stackrel{\text { 농 }}{\stackrel{\circ}{N}}$ & 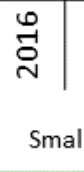 & $\begin{array}{c}\text { Small } \\
\text { Moderate }\end{array}$ & $\begin{array}{l}\text { erate } \\
\text { rge }\end{array}$ \\
\hline
\end{tabular}

\section{Measured Human Contacts}

Measured human contacts means a relatively low use of appointment scheduling, NQRs, and SMS channels. Despite relatively low human contacts, these patients exhibit a moderate level of consulting health care professionals. Their median comorbidity level is relatively stable over time (2010: 4 [3;5]; 2016: 4 [4;5]) in view of the population aging.

\section{Nonplanners}

Nonplanners constitute $7.16 \%(22,275 / 311,168)$ of the cohort. They have a relatively moderate-to-high human health care services consumption but a low tendency to use nonhuman means of communication (Table 2 and Figure 11). This group consists of a larger proportion of patients from the Arab sector $(9441 / 22,275,42.38 \%)$, which is associated with a higher proportion of nonimmigrants $(14,504 / 22,275,65.11 \%)$ and people with low SES level $(9669 / 22,275,43.40 \%)$. The preference of nonplanned human contact does not have a negative clinical effect. $\mathrm{HbA}_{1 \mathrm{c}}$ values of the nonplanners are controlled over time (2010: 7.26 [SD 1.52] mmol/mol; 2016: 7.22 [SD 1.45] $\mathrm{mmol} / \mathrm{mol}$ ) with very good follow-up and adherence levels. The proportion of missing follow-up measurements dropped over time, and this improvement is associated with an increased number of patients treated with diabetes medication (2010: 61.51\% [13,701/22,275]; 2016: $82.02 \%$ [18,271/22,275]) and better adherence over time (2010: $36.35 \%$ [8097/22,275]; 2016: 49.54\% [11,034/22,275]). 
Figure 11. Communication patterns for patients having measured human contacts without generally scheduling their visits.

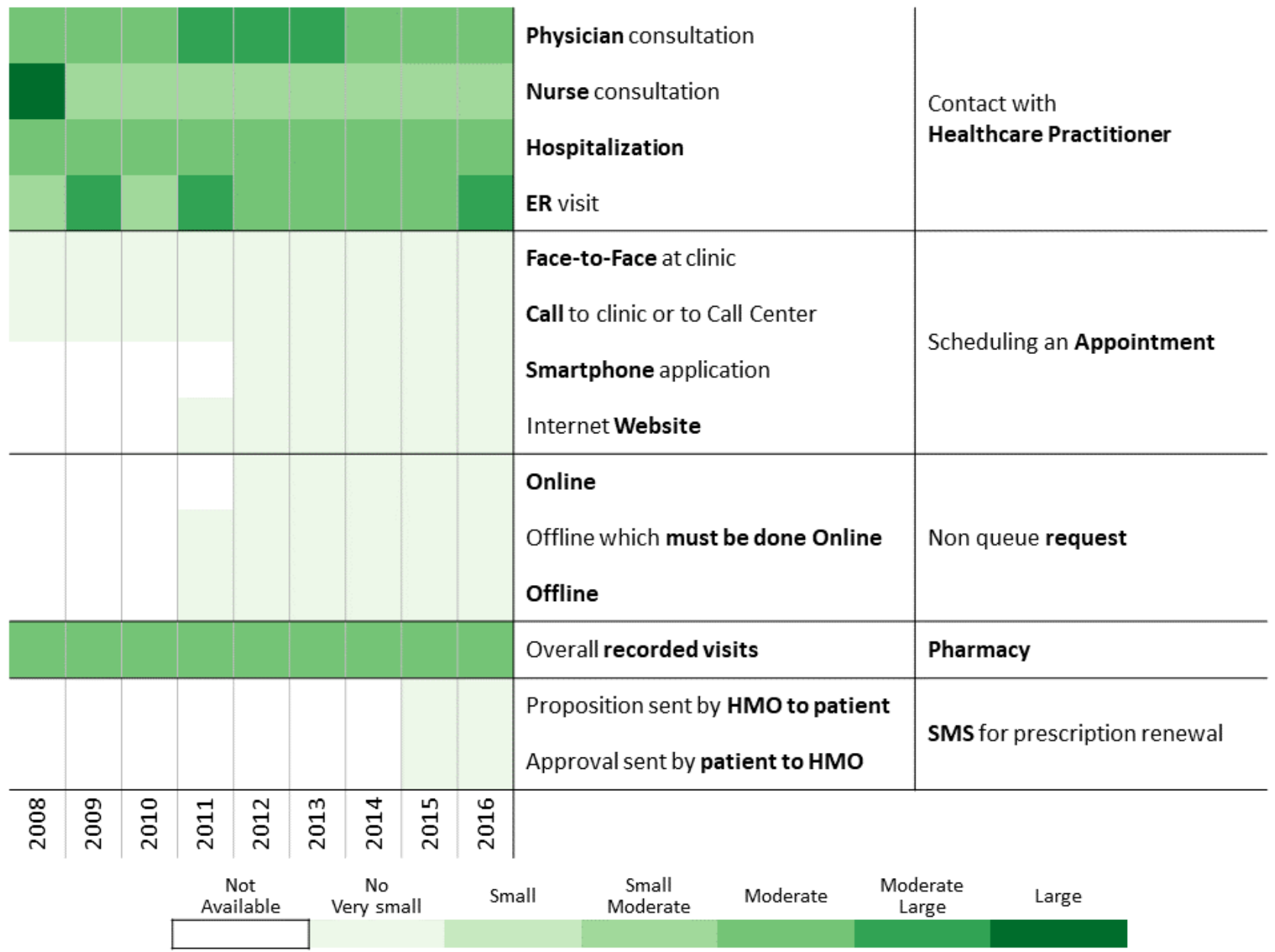

\section{Nursing Contacts}

The nursing-based contacts cluster constitutes $9.38 \%$ $(29,197 / 311,168)$ of the cohort (Table 2 and Figure 12), and its members prefer to consult with nurses. They also tend to schedule their appointments by using all available channels. The proportion of females is slightly higher than in the cohort $(15,463 / 29,197,52.99 \%)$, as are the proportions of nonimmigrant patients $(16,085 / 29,197,55.09 \%)$, Arab sector representation $(8599 / 29,197,29.45 \%)$, and low SES population $(10,158 / 29,197,34.79 \%)$. These demographics may explain the tendency to rely on contacts with health care professionals (human contacts). The average $\mathrm{HbA}_{1 \mathrm{c}}$ level is stable over time
(2010: 7.42 [SD 1.60] mmol/mol; 2016: 7.39 [SD 1.57] $\mathrm{mmol} / \mathrm{mol}$ ) and higher than the overall cohort. Although these results show merely a correlation between use of the nurse-patient channel and high levels of follow-up and adherence, they raise the hypothesis that the nurse-patient channel is very effective in inducing follow-up and adherence levels of patients. The percentage of patients who missed their annual measurements of follow-up metrics dropped over time (2008: around 15\%, 2016: around 4\%) and the adherence level increased (2010: 42.07\% [12,284/29,197]; 2016: 50.27\% $[14,676 / 29,197])$, as did the proportion of patients receiving treatment for diabetes (2010: 65.90\% [19,240/29,197]; 2016: $81.25 \%[23,722 / 29,197])$. 
Figure 12. Communication pattern changes for patients with diabetes having measured human contacts mainly by consulting nurses.

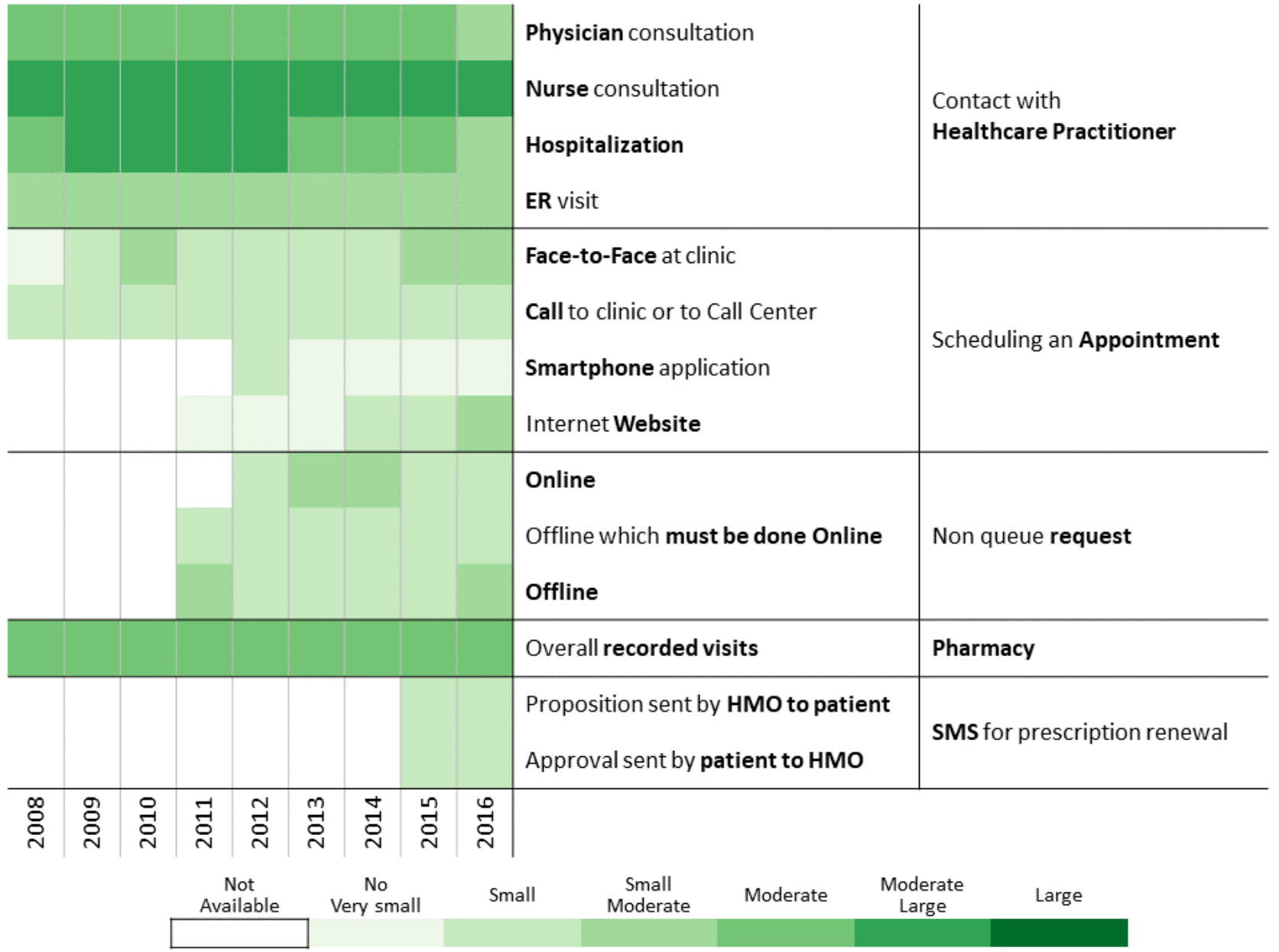

\section{High Electronic Contacts}

Patients in these clusters have a high level of use of online and electronic channels for communicating with the HMO (Table
3, Figure 13, and Figure 14). The website group (those using a personal computer) comprises $6.20 \%$ of the cohort $(19,277 / 311,168)$ and the smartphone (those using a mobile app) group comprises $4.27 \%(13,279 / 311,168)$. 
Figure 13. Communication pattern changes for patients having a high volume of electronic contacts over the health management organization website.

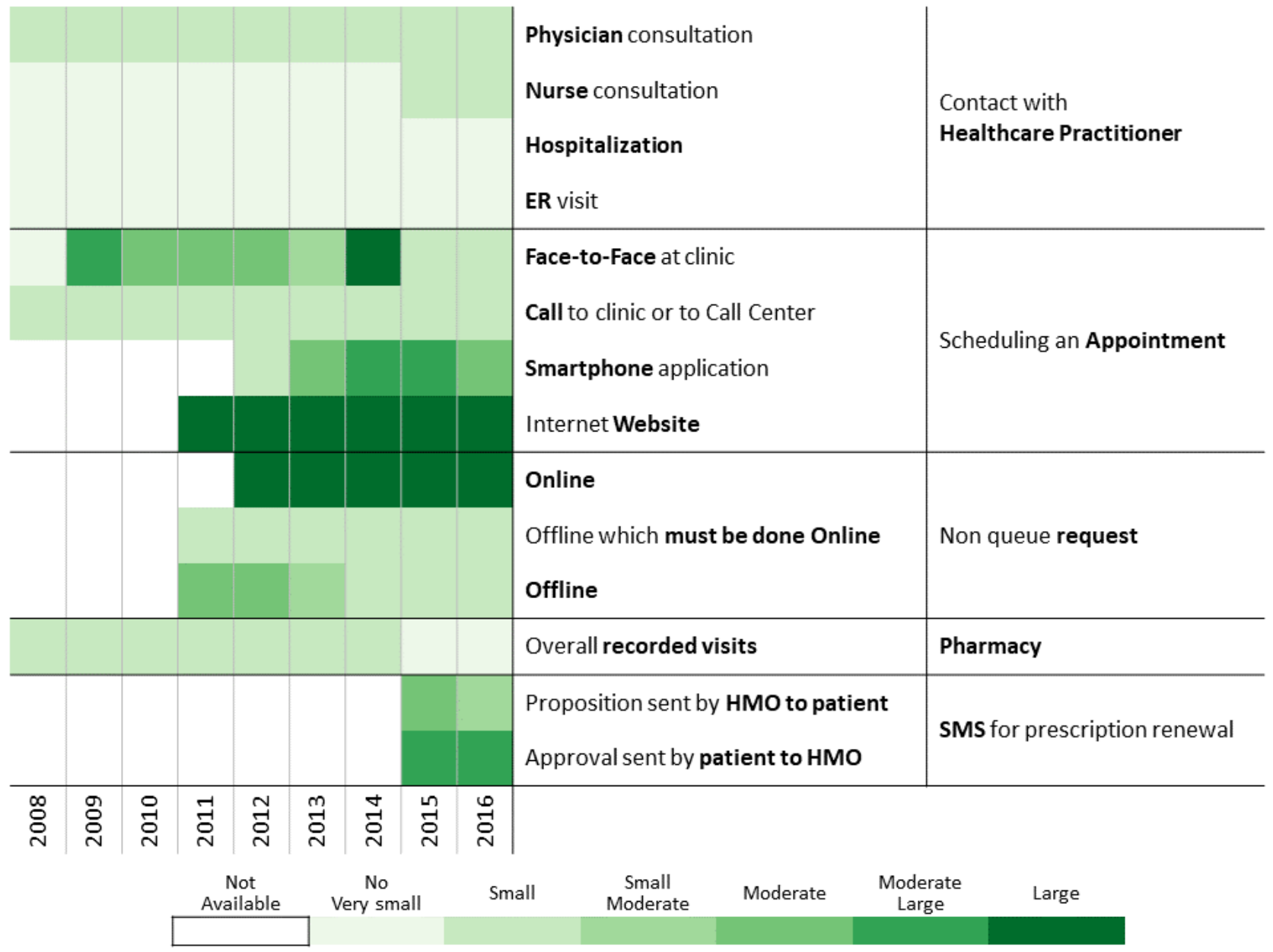


Figure 14. Communication pattern changes between 2008 and 2016 for patients with diabetes having a high volume of electronic contacts over the health management organization smartphone app.

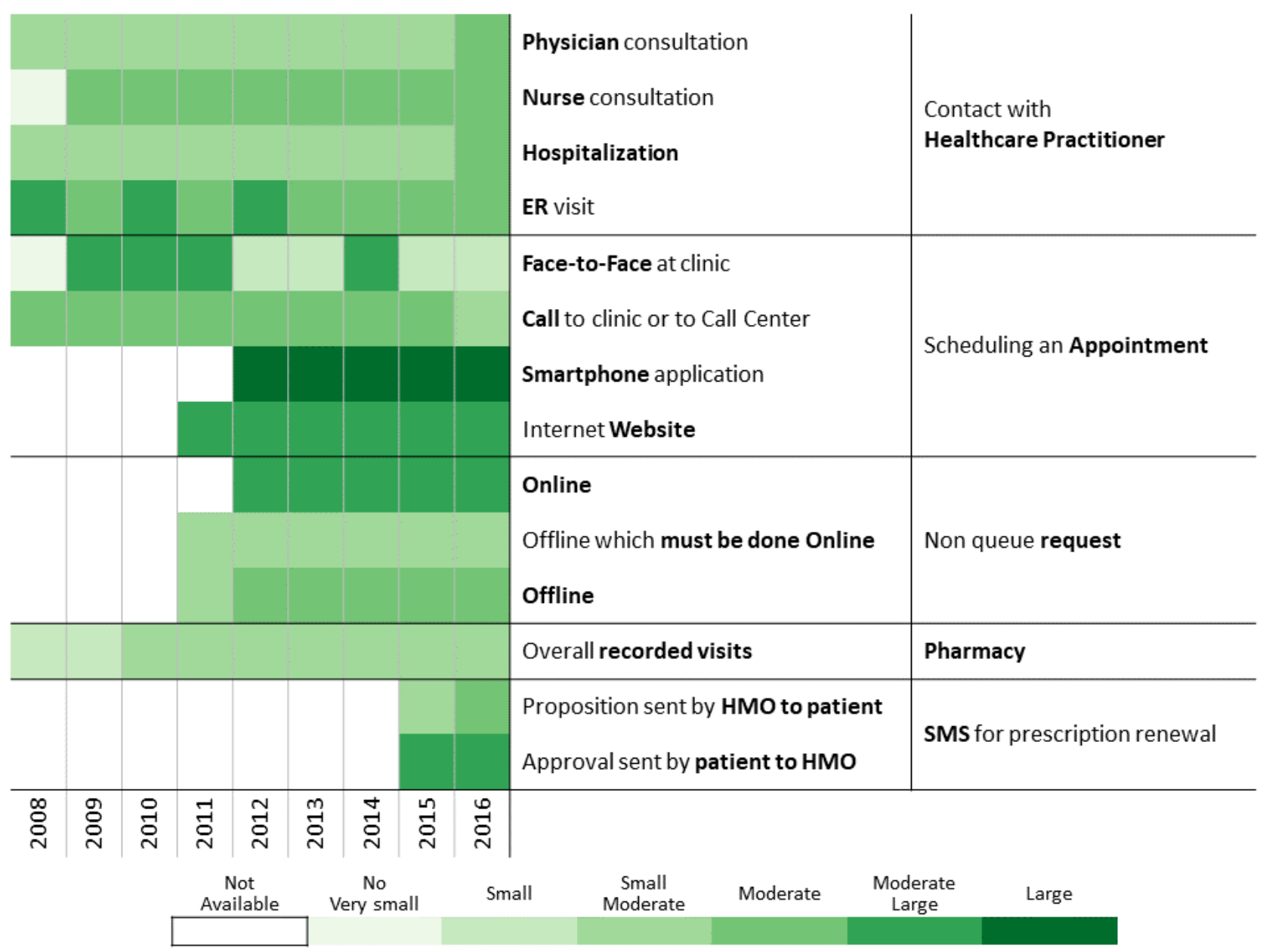

\section{Differences Between Website and Smartphone Clusters}

These patients exhibit substantial use of the most prominent technological interfaces developed in the past 20 years, with smartphone users being younger. This phenomenon might relate to the lower penetration rate of new technologies in older populations. The gender profiles of the two groups differ (website: males, 55.12\% [10,625/19,277]; smartphone: females: $54.60 \%$, [7250/13,279]). Moreover, in both groups (website/internet and smartphone users) there is a higher representation of the general population (respectively $95.96 \%$ $[18,498 / 19,277]$ and $82.66 \%[10,977 / 13,279]$ vs the overall population $77.8 \%(242,022 / 311,168])$ and a higher representation of medium and high SES (respectively, the website/internet users having a high SES are $51.67 \%$ [9961/19,277] and 45.04\% [5981/13,279] and the people of the smartphone cluster have a medium SES). This observation conforms to prior research, which found that lower SES populations gravitate toward smartphones $[60,61]$.

\section{Common Findings Between Website and Smartphone Clusters}

The heatmaps (Figure 13 and Figure 14) show high use of the website and smartphone app. Nevertheless, it is possible to see that the website cluster has a relatively low volume of direct contacts with health care professionals and prefers tools that enable nondirect and distant contacts. The clinical follow-up of these two clusters is better than that of the overall population, the proportion of missing follow-up indicators being lower in 2016 (Table 3). Furthermore, treatment adherence was better in 2016 than in the cohort population and also increased over the years in parallel with the number of newly treated patients. Patients in these two clusters tend to reduce their use of other means of communication and contacts with the HMO in favor of electronic media while maintaining a high follow-up quality and treatment adherence. By considering what seems like a positive impact of smartphone presence, the HMO should incorporate more functions into the smartphone app.

\section{Automated Interaction Early Adopters}

These patients are relatively young (Table 3 and Figure 15), and females and the general sector are largely represented $(15,034 / 26,290,57.19 \%$, and 19,310/26,290, 73.45\%, respectively). Despite being early adopters of new interaction services, this cluster uses all human contact-based services over time. The new automated interaction tools improve the quality of contacts with the $\mathrm{HMO}$ and do not serve as a replacement to previously existing channels. The comorbidity of this relatively young group is high (ACG: 5 [4;5]), and the proportion of missing bioclinical and follow-up measurements in 2016 is relatively low. Considering the aging process and the diabetes treatment policy change (lowering the $\mathrm{HbA}_{1 \mathrm{c}}$ threshold from $7.5 \%$ to $6.5 \%$ ), the number of patients taking a noninsulin 
treatment for diabetes increased over time (2010: $66.81 \%$ [17,565/26,290]; 2016: 83.73\% [22,012/26,290]). Moreover, the proportion of missing follow-up measurements decreased (eg, BMI: 2010, 6.83\% [1796/26,290]; 2016, 1.27\% [334/26,290]; $\mathrm{HbA}_{1 \mathrm{c}}, 2010,17.08 \%$ [4492/26,290]; 2016, 3.69\% [970/26,290]) and the proportion of adherence to treatment increased (2010: 44.85\% [11,792/26,290]; 2016: 54.17\%
$[14,240 / 26,290]$ in 2016). These results may indicate that the new tools allow patients to improve their engagement with the HMO. As their disease progresses, an increase in their services consumption is expected, but instead we observe a slight decrease in some of the services consumed. One contributing factor to the high prevalence of patients from the general sector in the cluster may be related to the sole use of Hebrew in the internet and smartphone app.

Figure 15. Communication pattern changes between 2008 and 2016 for patients with diabetes being early adopters of automated interaction tools.

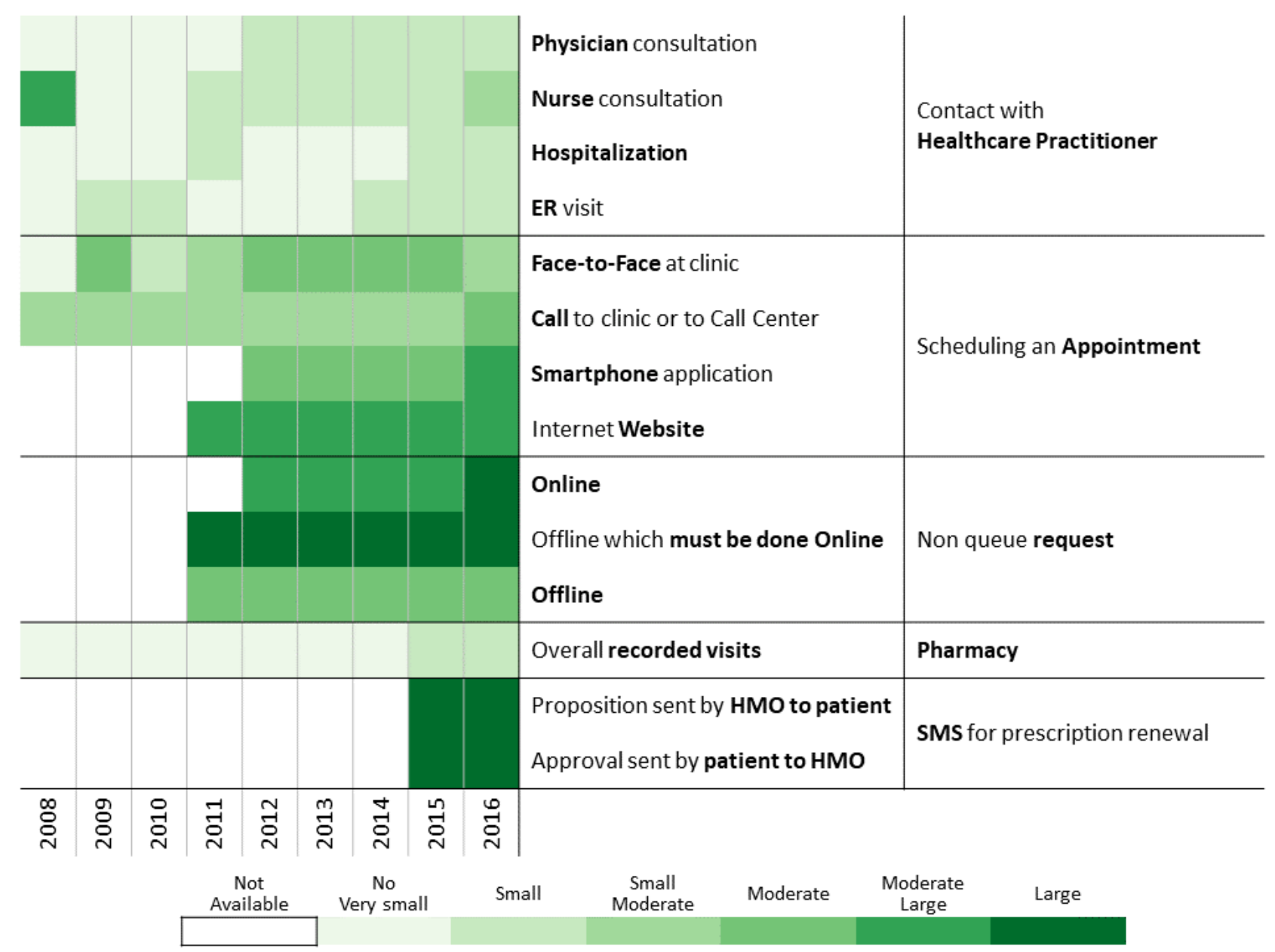

\section{Human-Based Contacts}

\section{Differences Between Nursing-Centered and Physician-Centered Clusters}

Patients having mainly human-based contacts (Table 3) with the HMO are divided in two clusters: nursing-centered
(7276/311,168, 2.34\%; Figure 16) and physician-centered $(8137 / 311,168,2.61 \%$; Figure 17). It should be noted that one of the main differences between these two populations is the proportion of patients missing their follow-up measurements in the physician-centered group. This highlights the importance of nurse involvement in patient follow-up. 
Figure 16. Communication pattern changes between 2008 and 2016 for patients with diabetes having mainly human-based contacts based on interactions with nursing.

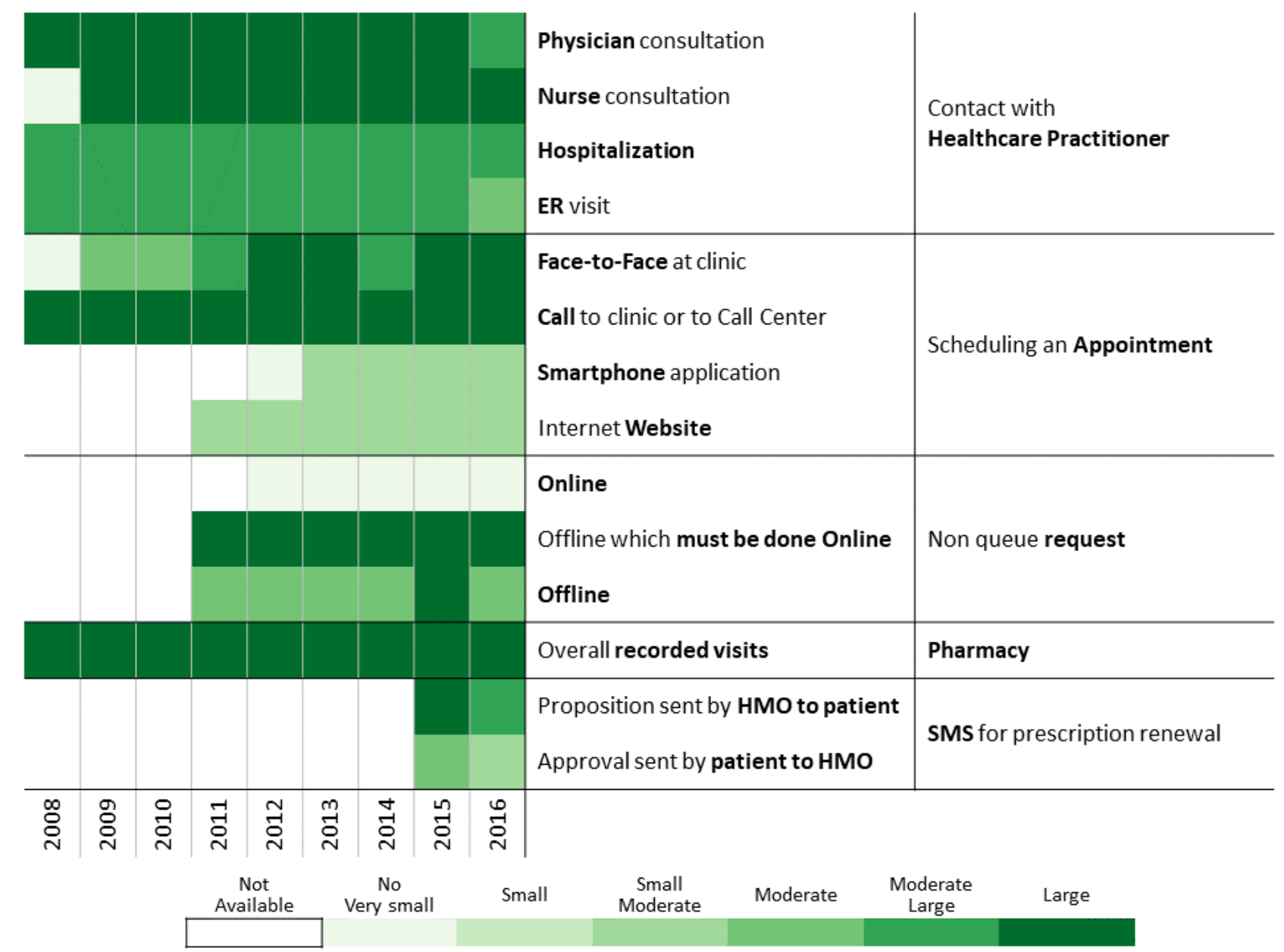


Figure 17. Communication pattern changes between 2008 and 2016 for patients with diabetes having mainly human-based contacts based on interactions with physicians.

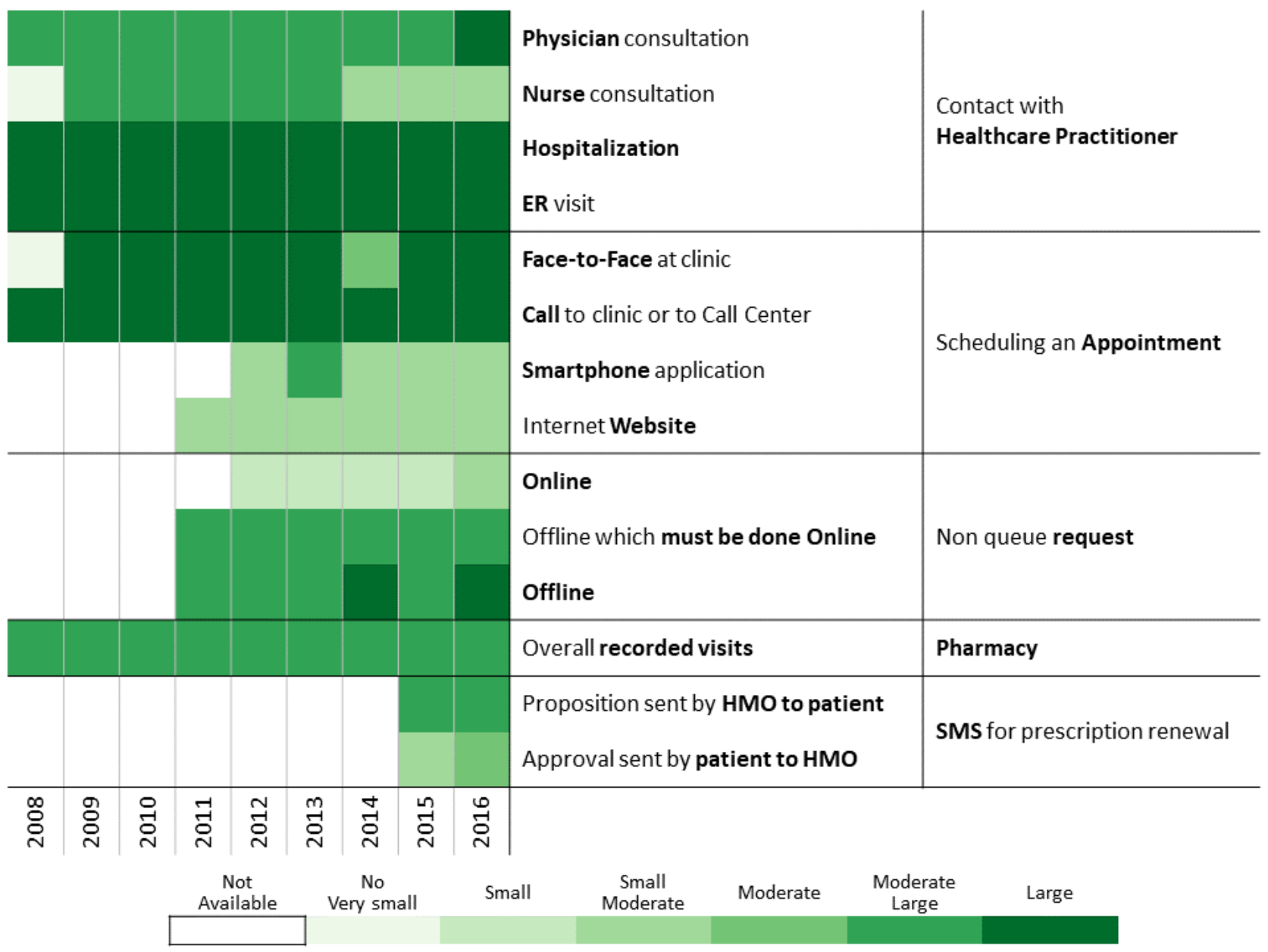

\section{Common Findings in Nursing-Centered and Physician-Centered Clusters}

These two clusters are relatively similar. In 2016, the proportion of female patients is relatively high and the population is older, with a majority of immigrants, and a higher representation of patients from medium-low SES groups. Patients in these two clusters had a relatively high ACG score over time. This increasing level of comorbidity can justify the high volume of nurse and physician consultations and high follow-up quality scores.

\section{Higher Resource Consumers Having Overall High Contacts and Electronic Driven Interactions}

Overall high contact represents $3.13 \%(9736 / 311,168)$ of the cohort (Table 3 and Figure 18) and the electronic driven interaction 4.71\% (14,647/311,168; Table 3 and Figure 19). They comprise older people (mean age 71 years) and a higher proportion of men and immigrants. From ethnicity and SES perspectives, the distributions for the overall high contact group resemble the cohort, while the electronic driven interaction group has a higher representation of the general sector (9241/9736, 94.92\%) and patients with high SES (4535/9736, $46.58 \%)$. 
Figure 18. Communication pattern changes between 2008 and 2016 for patients with diabetes having an overall high number of contacts with health care services.

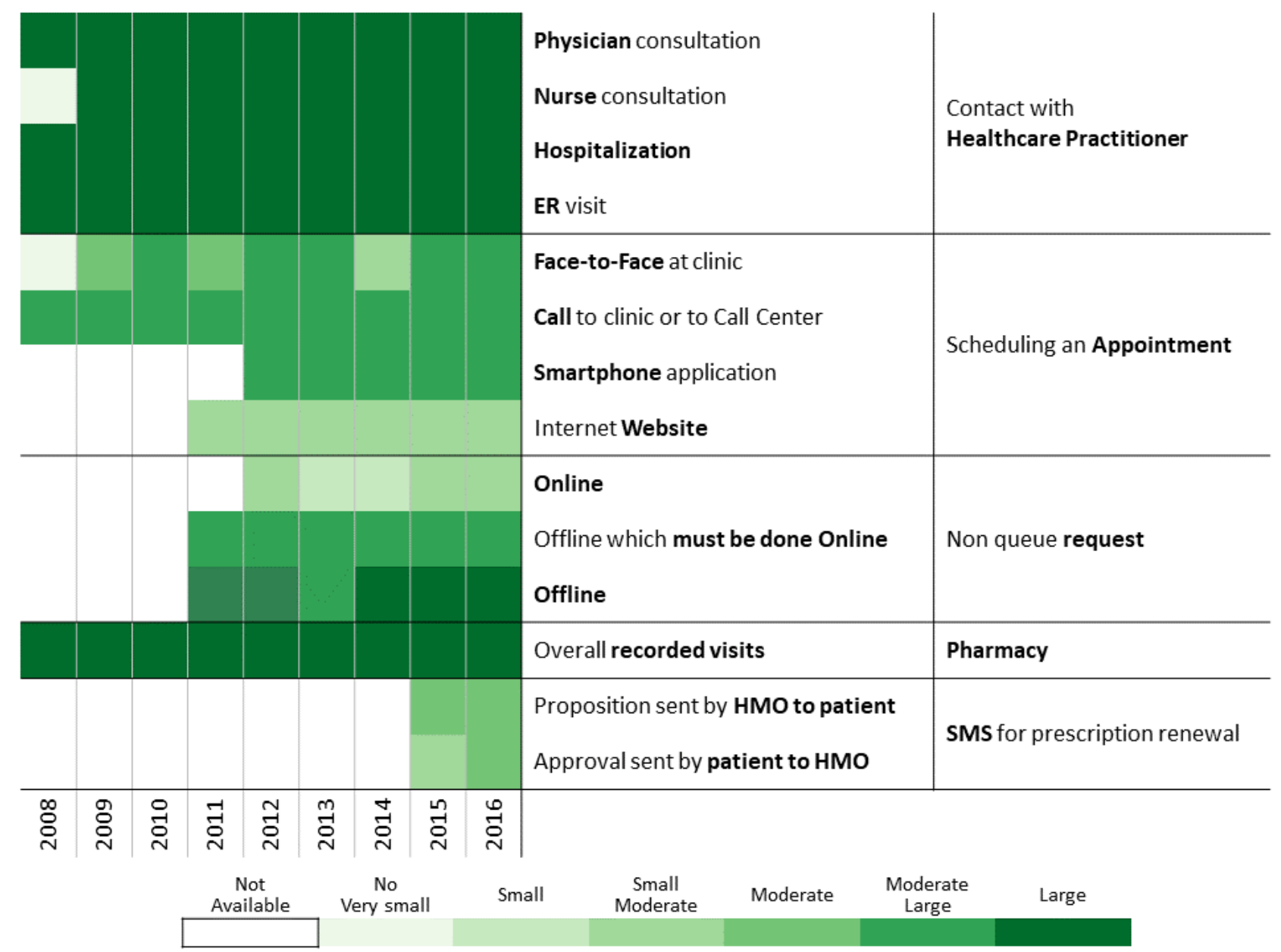


Figure 19. Communication pattern changes between 2008 and 2016 for patients with diabetes leading electronic-driven interaction with the health management organization.

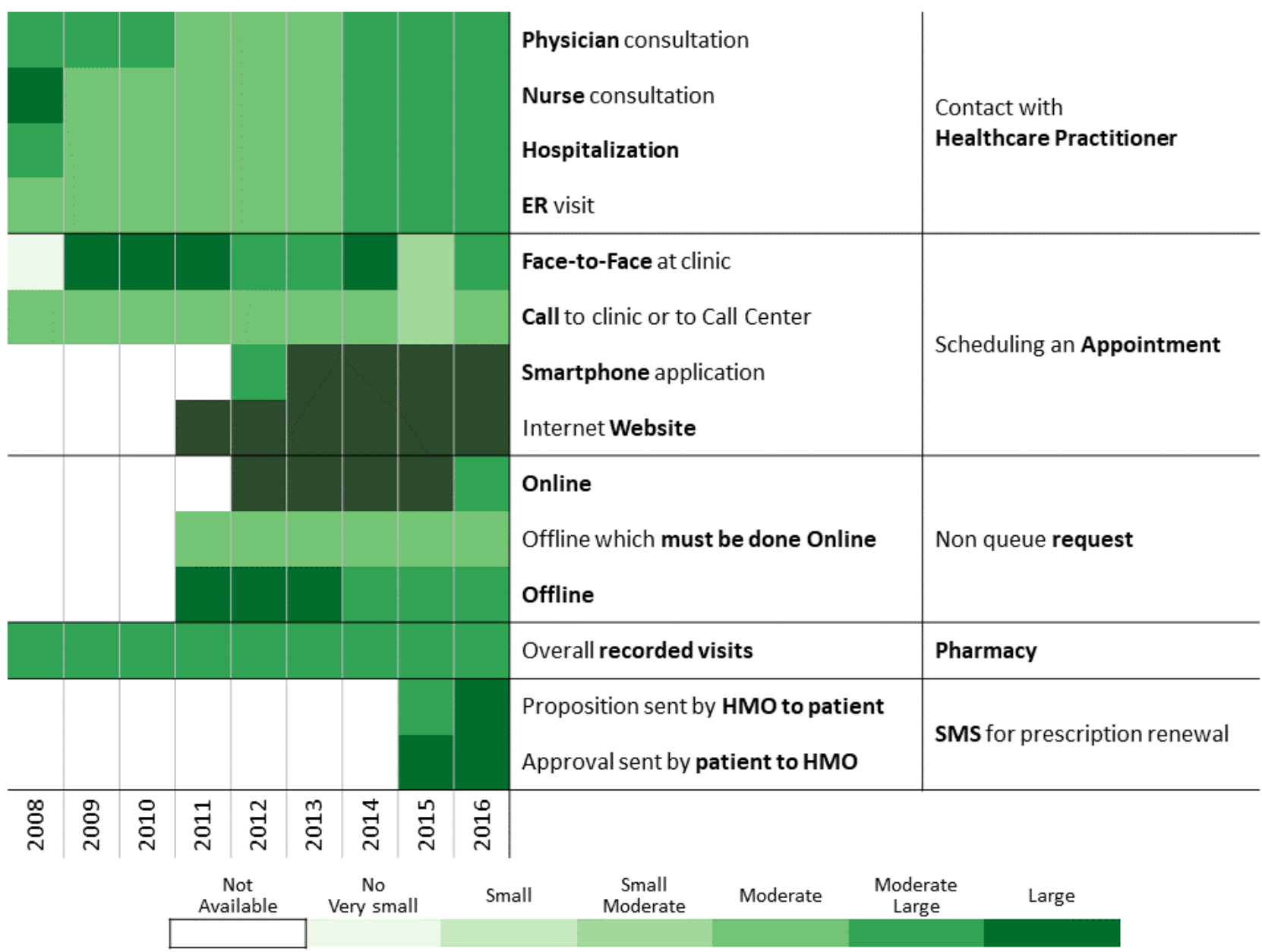

The main differences in the communicational profiles are in the interaction strength. The volume of contacts is high in both groups but higher for the overall high contact group compared with the electronic driven interaction group. This can be explained by the lower SES in the first cluster and Hebrew-speaking abilities, which may be lower than in the second. Lower SES may be considered as a proxy for confidence and ability to use technologies, and immigrant status, age, and SES as proxies for defining language abilities. The introduction of new communication channels over time only increased the global number of contacts. The large number of visits at the clinic may be justified by the higher comorbidity level. Follow-up measurements in both clusters are consistently better than the cohort. Treatment compliance is better for the electronic driven interaction cluster and increasing over time and in parallel to new communication channels introduction. Adherence to treatment of the overall high contact group is around $42 \%$ over time and not influenced by the addition of technological channels.

The age and comorbidity levels in these two clusters strongly influence the number of contacts with health care professionals over time and, as a by-product, the quality of follow-up improves. However, results suggest that SES and immigrant status influence the use of new technologies and increase the number of contacts with the HMO and patient adherence to treatment.

\section{Discussion}

\section{Principal Findings}

In this study, we identified and characterized 13 media profiles of patients. We have shown how communication behavior is influenced by the means of communication that the health organization provides to the patient. Additionally we have pointed out how different patients respond to technology-based communication and change the way they communicate with the health organization. Finally, we highlighted that some patients prefer to communicate with the organization by technological means and respond adequately to text messages, others prefer to communicate with the physician, and others with the nurse.

Identifying the channels of communication with the health organization and health care professionals preferred by each patient creates an opportunity to convey messages adapted to the patient in the most suitable communication channel. The greater the likelihood that the therapeutic message is received by the patient, the greater the patient's response to treatment, and the better the health of the patient.

\section{Strengths and Limitations}

Clalit insures and provides medical services to more than $54 \%$ of the Israeli population. It is the largest health care organization and insurer in Israel. However, although Clalit covers most of 
the population, the overall ethnic distribution of its health care customers does not accurately reflect the Israeli demographic composition: it has a higher proportion of Arabs, a lower proportion of ultra-Orthodox, and a higher proportion of members with a low SES [19].

\section{Patients With Diabetes and Generalization to the Overall Chronic Patient Population}

This retrospective analysis looks at Israeli patients treated by an Israeli HMO. The Israeli health care system, culture, and norms are factors affecting patient behavior in a specific way that do not allow a direct generalization of the results to other parts of the world.

This study overcomes a limitation of prior research dealing with the identification and description of health care customer communication patterns among individuals with diabetes in Clalit in 2015 [62]. Analyzing data that spans 9 years provides a better understanding of the changes of communication channel use over time and impact of socioeconomic factors, which cannot be easily and clearly understood with a 1-year snapshot.

\section{Effect of Digital Communication Tools}

The digital tools introduced between 2009 and 2016 for patients diagnosed with diabetes influence their follow-up and communication pathways with health care professionals. However, for more than half of the population investigated in this research, we found only a negligible influence of the digital tools on the communicational behavior (relatively low contacts, low and scheduled visits-low balance uses, measured human contacts, human-based contacts, and overall high contact clusters, $54.30 \%$ ).

Digital tools, such as NQRs and SMS for prescription renewal, allow patients to reduce or avoid visits to the clinic or hospital. For patients initially having a relatively low number of health care practitioner contacts over time, these digital tools may induce a reduction in the number of visits to the clinic or nurse station. Eliminating potential visits due to the introduction of digital tools might influence the follow-up quality because these visits could have served as another opportunity for a human contact with the patient (eg, for discussing treatment issues) or at least to measure the patient's condition [61,62]. Almost a third of the research population use technology to reduce their engagement with health care professionals. Not surprisingly, these are patients who tend to have a relatively small number of interactions with health care professionals (relatively low contacts-tech-based, low and scheduled visits-moderate nonvisits, electronic users, and automated interaction early adopters, $32.10 \%$ ). We would like to emphasize that the results do not show that the introduction of digital tools deteriorates the health condition of this one-third of the population. Nor do we claim that the reduction in visits to health care professionals is inherently an unwanted outcome. On the contrary, this is exactly what EMR systems are designed for. Rather, we claim that for targeted populations, which do not communicate efficiently with health care professionals, new digital tools might have negative consequences on the quality of the follow-up. This danger can be mitigated by using additional, human-based communication channels, akin to the guided-care approach [63], which have already proven to be effective. We can now build tools to identify these patients based on their behavior and target the efforts on the population that needs it.

For about $13.60 \%$ of the population, the introduction of new and digital channels in the communication arsenal of the HMO is effective. These are the patients who belong to the following clusters: high electronic contacts-website, high electronic contacts-smartphone, and electronic driven interaction.

Patients in the low-to-moderate clusters were found to have different health outcomes due to a lower health care services consumption impacting their follow-up quality and adherence to treatment. On the other hand, patients who consume more services, the ones in the moderate-to-high clusters, have better health outcomes (despite being generally older and with a higher ACG). To sum up, it looks like that the effect of digital communication tools is to improve the follow-up and adherence to treatment instead of replacing human interactions with health care professionals.

\section{Current and Potential Future Directions}

As time progresses, the population becomes more accustomed to using digital channels and new communication channels are introduced (eg, an online counseling services with video calls to physicians when clinics are closed, available in Clalit since 2017). Communication patterns should be monitored in the face of the rapid changes in population behavior and services offered.

Furthermore, by tuning its communication tools to patient preferences and special needs (eg, by translating the user interfaces of electronic communications tools to languages such as Arabic, English, Russian, Amharic, French, Spanish), the health organization would realize the following:

- Improve and increase accessibility to health care services, achieve better patient engagement and responsiveness to treatment, and improve quality of treatment and treatment experience within existing budgetary constraints

- Increase patient engagement with the treatment process by transforming the communication scheme with each patient to a more proactive scheme to better fit patient profile

- Allow patient-reported outcome measures [64] for some follow-up measurements such as BMI (or more specifically, weight) and smoking status in an effort to reduce nurse work (over)load while continuing and improving patient follow-up

Finally, we investigated only diabetic patients. This research and its related methodology can be generalized and extended to other chronic and acute patients.

\section{Conclusion}

In this paper we presented and demonstrated a methodology to identify communication profiles over time within health care systems. We applied this methodology to the data of more than 300,000 diabetic patients from Clalit Health Services in Israel and found 13 such profiles. These profiles enabled health care professionals and the insurer to adapt the communication and message conveyed to patients based on their communication profile. This methodology can be applied in other organizations in other geographical locations. 
We found that $22.40 \%$ of patients have very low health services consumption, and an additional $45.90 \%$ have low-to-moderate health services consumption, which indicated a low level of patient engagement. We showed that the introduction of technological communication channels didn't substantially improve the engagement of these patients and for some of the patients it even reduced communication with health care professionals. Based on these findings, we think that improving patient engagement cannot rely solely on technological solutions; rather, these solutions must be accompanied by complementary means [65].

\section{Acknowledgments}

The research was supported by a grant from the Israel National Institute for Health Policy (\#188-15).

\section{Conflicts of Interest}

None declared.

\section{References}

1. Axén I, Bodin L, Bergström G, Halasz L, Lange F, Lövgren P, et al. Clustering patients on the basis of their individual course of low back pain over a six month period. BMC Musculoskelet Disord 2011 May 17;12:99 [FREE Full text] [doi: 10.1186/1471-2474-12-99] [Medline: 21586117]

2. Rai A, Chen L, Pye J, Baird A. Understanding determinants of consumer mobile health usage intentions, assimilation, and channel preferences. J Med Internet Res 2013 Aug 02;15(8):e149 [FREE Full text] [doi: 10.2196/jmir.2635] [Medline: 23912839]

3. Hoffman AS, Volk RJ, Saarimaki A, Stirling C, Li LC, Härter M, et al. Delivering patient decision aids on the Internet: definitions, theories, current evidence, and emerging research areas. BMC Med Inform Decis Mak 2013;13 Suppl 2:S13 [FREE Full text] [doi: 10.1186/1472-6947-13-S2-S13] [Medline: 24625064]

4. Beck F, Richard J, Nguyen-Thanh V, Montagni I, Parizot I, Renahy E. Use of the internet as a health information resource among French young adults: results from a nationally representative survey. J Med Internet Res 2014;16(5):e128 [FREE Full text] [doi: 10.2196/jmir.2934] [Medline: 24824164]

5. Moick M, Terlutter R. Physicians' motives for professional internet use and differences in attitudes toward the internet-informed patient, physician-patient communication, and prescribing behavior. Med 20 2012;1(2):e2 [FREE Full text] [doi: 10.2196/med20.1996] [Medline: 25075230]

6. Kritz M, Gschwandtner M, Stefanov V, Hanbury A, Samwald M. Utilization and perceived problems of online medical resources and search tools among different groups of European physicians. J Med Internet Res 2013;15(6):e122 [FREE Full text] [doi: 10.2196/jmir.2436] [Medline: 23803299]

7. Dugdale DC, Epstein R, Pantilat SZ. Time and the patient-physician relationship. J Gen Intern Med 1999 Jan;14 Suppl 1:S34-S40 [FREE Full text] [doi: 10.1046/j.1525-1497.1999.00263.x] [Medline: 9933493]

8. Weiner JP. Doctor-patient communication in the e-health era. Isr J Health Policy Res 2012;1(1):33 [RREE Full text] [doi: 10.1186/2045-4015-1-33] [Medline: 22929000]

9. Peleg R, Avdalimov A, Freud T. Providing cell phone numbers and email addresses to patients: the physician's perspective. BMC Res Notes 2011 Mar 23;4:76 [FREE Full text] [doi: 10.1186/1756-0500-4-76] [Medline: 21426591]

10. Peleg R, Nazarenko E. Providing cell phone numbers and e-mail addresses to patients: the patient's perspective, a cross sectional study. Isr J Health Policy Res 2012 Aug 28;1(1):32 [FREE Full text] [doi: 10.1186/2045-4015-1-32] [Medline: 22929801]

11. Ha JF, Longnecker N. Doctor-patient communication: a review. Ochsner J 2010;10(1):38-43 [FREE Full text] [Medline: 21603354]

12. Rothlind E, Fors U, Salminen H, Wändell P, Ekblad S. Circling the undefined: a grounded theory study of intercultural consultations in Swedish primary care. PLoS One 2018;13(8):e0203383 [FREE Full text] [doi: 10.1371/journal.pone.0203383] [Medline: 30161227]

13. Shang L, Zuo M, Ma D, Yu Q. The antecedents and consequences of health care professional-patient online interactions: systematic review. J Med Internet Res 2019 Sep 25;21(9):e13940 [FREE Full text] [doi: 10.2196/13940] [Medline: 31573908]

14. Lupton D. Digital health and health care. In: Scambler G, editor. Sociology as Applied to Health and Medicine, 7 th Edition. London: Macmillan Publishers; 2018:277-290.

15. Husted GR, Weis J, Teilmann G, Castensøe-Seidenfaden P. Exploring the influence of a smartphone app (Young with Diabetes) on young people's self-management: qualitative study. JMIR Mhealth Uhealth 2018 Feb 28;6(2):e43 [FREE Full text] [doi: 10.2196/mhealth.8876] [Medline: 29490897]

16. Eysenbach G. Infodemiology and infoveillance: framework for an emerging set of public health informatics methods to analyze search, communication and publication behavior on the Internet. J Med Internet Res 2009;11(1):e11 [FREE Full text] [doi: 10.2196/jmir.1157] [Medline: 19329408]

17. Henao R, Murray J, Ginsburg G, Carin L, Lucas JE. Patient clustering with uncoded text in electronic medical records. AMIA Annu Symp Proc 2013;2013:592-599 [FREE Full text] [Medline: 24551361] 
18. Sewitch MJ, Leffondré K, Dobkin PL. Clustering patients according to health perceptions: relationships to psychosocial characteristics and medication nonadherence. J Psychosom Res 2004 Mar;56(3):323-332. [doi: 10.1016/S0022-3999(03)00508-7] [Medline: 15046970]

19. Benis A, Harel N, Barak Barkan R, Srulovici E, Key C. Patterns of patients' interactions with a health care organization and their impacts on health quality measurements: protocol for a retrospective cohort study. JMIR Res Protoc 2018 Nov 07;7(11):e10734 [FREE Full text] [doi: 10.2196/10734] [Medline: 30404769]

20. Webster C. EHR business process management: from process mining to process improvement to process usability. Healthcare Systems Process Improvement Conf., Las Vegas 2012:1-6.

21. Markides M. The importance of good communication between patient and health professionals. J Ped Hematol Oncol 2011;33:S123-S125. [doi: 10.1097/mph.0b013e318230e1e5]

22. Paternotte E, van Dulmen S, van der Lee N, Scherpbier AJ, Scheele F. Factors influencing intercultural doctor-patient communication: a realist review. Patient Educ Couns 2015 Apr;98(4):420-445. [doi: 10.1016/j.pec.2014.11.018] [Medline: 25535014]

23. Cohen-Stavi CJ, Balicer RD, Roberts ML. Innovation in health care for proactive care delivery and strategic clinical decision-making: integrating research, technology and practice. Public Health Panorama 2018 Sep;4(3):470-474 [FREE Full text] [doi: 10.1093/oxfordjournals.pubmed.a043518]

24. Jaffe DH, Flaks-Manov N, Benis A, Gabay H, DiBonaventura M, Rosenbaum H, et al. Population-based cohort of 500 patients with Gaucher disease in Israel. BMJ Open 2019 Jan 21;9(1):e024251 [FREE Full text] [doi: 10.1136/bmjopen-2018-024251] [Medline: 30670517]

25. Rennert G, Peterburg Y. Prevalence of selected chronic diseases in Israel. Isr Med Assoc J 2001 Jun;3(6):404-408 [FREE Full text] [Medline: 11433630]

26. Karpati T, Cohen-Stavi CJ, Leibowitz M, Hoshen M, Feldman BS, Balicer RD. Towards a subsiding diabetes epidemic: trends from a large population-based study in Israel. Popul Health Metr 2014;12(1):32 [FREE Full text] [doi:

10.1186/s12963-014-0032-y] [Medline: 25400512]

27. Ifrah A, Libroder C, Karolinsky D. In: Shohat T, Keinan-Boker L, Ifrah A, Libruder C, editors. Highlights of Health in Israel 2016. Israel: Israel Center for Disease Control, Israel Ministry of Health; May 2017:1-111.

28. Fayyad U, Piatetsky-Shapiro G, Smyth P. From data mining to knowledge discovery in databases. AI Magazine 1996;17(3):37. [doi: 10.1609/aimag.v17i3.1230]

29. Fayyad U, Piatetsky-Shapiro G, Smyth P. The KDD process for extracting useful knowledge from volumes of data. Commun ACM 1996;39(11):27-34. [doi: 10.1145/240455.240464]

30. Frawley P, Piatetsky-Shapiro G, Matheus CJ. Knowledge discovery in databases: an overview. AI Magazine 1992;13(3):57-70 [FREE Full text] [doi: 10.1609/aimag.v13i3.1011]

31. Zaki M, Meira W. Data Mining and Analysis: Fundamental Concepts and Algorithms. Cambridge: Cambridge University Press; 2014.

32. Mitchell T. Machine Learning. New York: McGraw Hill; 1997.

33. O'Connor PJ, Bodkin NL, Fradkin J, Glasgow RE, Greenfield S, Gregg E, et al. Diabetes performance measures: current status and future directions. Diabetes Care 2011 Jul;34(12):1651-1659 [FREE Full text] [doi: 10.2337/dc11-0735] [Medline: 21709298]

34. Turner M, Burns SM, Knight L, Ward K, Garo A, Morris T, et al. Weight management practices among heart and vascular health care providers in an ambulatory setting. Medsurg Nurs 2012;21(4):222-232. [Medline: 22966525]

35. Use of glycated haemoglobin (HbA1c) in the diagnosis of diabetes mellitus: abbreviated report of a WHO consultation. Geneva: World Health Organization; 2011.

36. Reid RJ, Roos NP, MacWilliam L, Frohlich N, Black C. Assessing population health care need using a claims-based ACG morbidity measure: a validation analysis in the Province of Manitoba. Health Serv Res 2002 Oct;37(5):1345-1364 [FREE

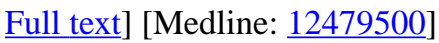

37. Norwegian Institute of Public Health. Guidelines for ATC classification and DDD assignment. Oslo: WHO Collaborating Centre for Drug Statistics Methodology; 2018. URL: https://www.drugsandalcohol.ie/29364/1/ WHO\%20Collaborating\%20Centre\%20for\%20Drug\%20Statistics\%20Methodology.pdf [accessed 2020-07-24]

38. Ben-Gal I. Outlier detection. In: Maimon O, editor. Data Mining and Knowledge Discovery Handbook, 2nd Edition. New York: Springer; 2011:117-130.

39. Leys C, Ley C, Klein O, Bernard P, Licata L. Detecting outliers: do not use standard deviation around the mean, use absolute deviation around the median. J Exper Soc Psychol 2013 Jul;49(4):764-766. [doi: 10.1016/j.jesp.2013.03.013]

40. Bansal R, Gaur N, Singh S. Outlier detection: applications and techniques in data mining. 2016 Presented at: 2016 6th International Conference_Cloud System and Big Data Engineering (Confluence); 2016; Noida. [doi: 10.1109/confluence.2016.7508146]

41. Rahm E, Hong H. Data cleaning: problems and current approaches. IEEE Bull Tech Comm Data Engineer 2000;23:1-11 [FREE Full text]

42. Han J, Kamber M. Data Mining: Concepts and Techniques, 3rd Edition. Burlington: Morgan Kaufmann; 2011. 
43. Escalante HJ. A comparison of outlier detection algorithms for machine learning. In: Memoria del XIV Congreso Internacional de Computación (CIC 2005). 2005 Presented at: Congreso Internacional en Computacion - IPN, 2005; September 2005; México URL: https://pdfs.semanticscholar.org/cf06/9b7460ce1b5a0434a6a19f420544a780f35d.pdf [doi: 10.1002/0471725382.ch5]

44. Chandola V, Banerjee A, Kumar V. Anomaly detection: a survey. ACM Comput Surv 2009;41(3):1-58. [doi: $10.1145 / 1541880.1541882]$

45. Fodor A. A survey of dimension reduction techniques. In: Technical Report. CA (US): Lawrence Livermore National Laboratory; 2002.

46. Cunningham P. Dimension reduction. In: Cord M, Cunningham P, editors. Machine Learning Techniques for Multimedia: Case Studies on Organization and Retrieval. Berlin, Heidelberg: Springer; 2008:91-112.

47. Rokach L. A survey of clustering algorithms. In: Maimon O, Rokach L, editors. Data Mining and Knowledge Discovery Handbook, 2nd Edition. New York: Springer; 2011:269-298.

48. MacQueen J. Some methods for classification and analysis of multivariate observations. 1967 Presented at: Proc Fifth Berkeley Symp Math Stat Probability Vol 1; 1967; Berkeley p. 281-297 URL: https://projecteuclid.org/euclid.bsmsp/ 1200512992

49. Ray S, Turi R. Determination of number of clusters in K-means clustering and application in colour segmentation. 1999 Presented at: The 4th International Conference on Advances in Pattern Recognition and Digital Techniques; 1999 ; Victoria.

50. Ester M, Kriegal H, Sander J, Xu X. A density-based algorithm for discovering clusters in large spatial databases with noise. 1996 Presented at: Proceedings of the Second International Conference on Knowledge Discovery and Data Mining (KDD-96); 1996; Munchen.

51. Ankerst M, Breunig M, Kriegel H, Sander J. Optics: ordering points to identify the clustering structure. 1999 Presented at: ACM SIGMOD Record; 1999; New York. [doi: 10.1145/304182.304187]

52. Madeira SC, Oliveira AL. Biclustering algorithms for biological data analysis: a survey. IEEE/ACM Trans Comput Biol Bioinform 2004;1(1):24-45. [doi: 10.1109/TCBB.2004.2] [Medline: 17048406]

53. Zhao H, Liew A, Wang D, Yan H. Biclustering analysis for pattern discovery: current techniques, comparative studies and applications. Curr Bioinform 2012 Mar 01;7(1):43-55. [doi: 10.2174/157489312799304413]

54. Aggarwal C, Han J. Frequent Pattern Mining. New York: Springer International Publishing; 2014.

55. Card SK, Mackinlay J, Shneiderman B, editors. Readings in Information Visualization: Using Vision to Think. Burlington: Moegan Kaufmann; 1999:712.

56. van der Aalst W. Process Mining, 2nd Edition. Berlin: Springer-Verlag; 2016.

57. Dowle M, Srinivasan A, Gorecki J. CRAN: package data.table. URL: https://cran.r-project.org/web/packages/data.table/ [accessed 2020-07-24]

58. Mächler M, Rousseeuw P, Struyf A, Hubert M, Hornik K. Cluster: cluster analysis basics and extensions. 2012. URL: https://cran.r-project.org/web/packages/cluster/cluster.pdf [accessed 2020-07-24]

59. Warnes GR, Bolker B, Bonebakker L, Liaw A, Huber W, Lumley T, et al. gplots: Various R programming tools for plotting data, version 2.17.0. 2015. URL: https://CRAN.R-project.org/package=gplots [accessed 2020-07-26]

60. Duran JL. A Smart (Phone) Solution: Improving Early Intervention for Families of Low Socioeconomic Status [Thesis]. St. Louis: Washington University in St. Louis School of Medicine; 2015.

61. Ernsting C, Dombrowski SU, Oedekoven M, Kanzler M, Kuhlmey A, Gellert P. Using smartphones and health apps to change and manage health behaviors: a population-based survey. J Med Internet Res 2017 Apr 05;19(4):e101 [FREE Full text] [doi: 10.2196/jmir.6838] [Medline: 28381394]

62. Benis A, Harel N, Barkan R, Sela T, Feldman B. Identification and description of healthcare customer communication patterns among individuals with diabetes in Clalit Health Services: a retrospective database study. Stud Health Technol Inform 2017;244:18-22. [doi: 10.3233/978-1-61499-824-2-18] [Medline: 29039369]

63. Aliotta SL, Grieve K, Giddens JF, Dunbar L, Groves C, Frey K, et al. Guided care: a new frontier for adults with chronic conditions. Prof Case Manag 2008;13(3):151-158. [doi: 10.1097/01.PCAMA.0000319968.76605.b3] [Medline: 18562909]

64. Nelson EC, Eftimovska E, Lind C, Hager A, Wasson JH, Lindblad S. Patient reported outcome measures in practice. BMJ 2015 Feb 10;350:g7818. [doi: 10.1136/bmj.g7818] [Medline: 25670183]

65. Roosan D, Weir C, Samore M, Jones M, Rahman M, Stoddard GJ, et al. Identifying complexity in infectious diseases inpatient settings: an observation study. J Biomed Inform 2017 Jul;71S:S13-S21 [FREE Full text] [doi: 10.1016/j.jbi.2016.10.018] [Medline: 27818310]

\section{Abbreviations}

ACG: adjusted clinical groups

Clalit: Clalit Health Services

CRI: Clalit Research Institute

DWH: data warehouse

EMR: electronic medical record 
ER: emergency department

HbA $_{1 \mathbf{c}}$ : glycated hemoglobin

HMO: health management organization

KDD: knowledge discovery in databases

NQR: nonqueue request

SES: socioeconomic status

PDC: proportion of days covered

SMS: short message service

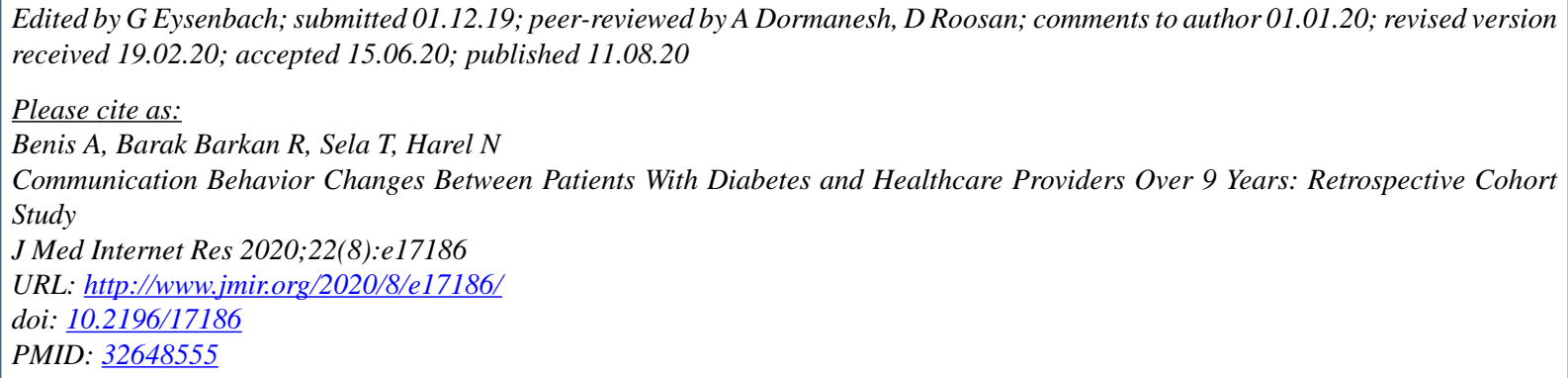

(C)Arriel Benis, Refael Barak Barkan, Tomer Sela, Nissim Harel. Originally published in the Journal of Medical Internet Research (http://www.jmir.org), 11.08.2020. This is an open-access article distributed under the terms of the Creative Commons Attribution License (https://creativecommons.org/licenses/by/4.0/), which permits unrestricted use, distribution, and reproduction in any medium, provided the original work, first published in the Journal of Medical Internet Research, is properly cited. The complete bibliographic information, a link to the original publication on http://www.jmir.org/, as well as this copyright and license information must be included. 